\title{
ACE2/ANG-(1-7)/Mas Receptor Axis Activation Prevents Inflammation, Glial Activation And Cognitive Decline In a Rat Model of STZ Induced Impairment of Learning and Memory
}

\section{Virendra Tiwari}

CSIR-CDRI: Central Drug Research Institute

Jitendra Singh

CSIR-CDRI: Central Drug Research Institute

Priya Tiwari

CSIR-CDRI: Central Drug Research Institute

\section{Swati Chaturvedi}

CSIR-CDRI: Central Drug Research Institute

\section{Shivangi Gupta}

CSIR-CDRI: Central Drug Research Institute

\section{Akanksha Mishra}

CSIR-CDRI: Central Drug Research Institute

\section{Sonu Singh}

CSIR-CDRI: Central Drug Research Institute

Muhammad Wahajuddin

CSIR-CDRI: Central Drug Research Institute

\section{Kashif Hanif}

CSIR-CDRI: Central Drug Research Institute

Shubha Shukla ( $\nabla$ shubha111@gmail.com )

CSIR-CDRI: Central Drug Research Institute https://orcid.org/0000-0002-2965-1128

\section{Research Article}

Keywords: Angiotensin-converting enzyme 2, Morris water maze, MasR, Ang (1-7), NLRP3, inflammation

Posted Date: October 26th, 2021

DOI: https://doi.org/10.21203/rs.3.rs-1002782/v1

License: (c) (1) This work is licensed under a Creative Commons Attribution 4.0 International License.

Read Full License 
Page $2 / 33$ 


\section{Abstract}

Activation of the renin-angiotensin system (RAS), mediated by Angiotensin converting enzyme/Angiotensin II/Angiotensin receptor-1 (ACE/Ang II/AT1 R) axis elicits amyloid pathology, induces neurodegeneration and cognitive impairment leading to Alzheimer's disease (AD). On the contrary, Angiotensin converting enzyme2 (ACE2) produces Ang -(1-7) which binds with the Mas receptor and counters ACE/Ang II/AT1 axis. To date, the involvement of ACE2/Ang-(1-7)/MasR axis in etiology and progression of $A D$ largely remains to be elucidated. Hence, the present study is aimed to determine the role of ACE2/Ang-(1-7)/MasR axis in STZ induced model of neurodegeneration using Diminazene aceturate (DIZE), an ACE2 activator in both in vitro/ in vivo experimental conditions. Interestingly, ROS content and oxidative stress burden in N2A cells were found to be attenuated along with a decrease in enzymatic activity of AChE following DIZE treatment. In contrast, activation of this axis led to altered mitochondrial membrane potential (MMP) in addition to ablated intracellular $\mathrm{Ca}^{2+}$ influx. ACE2/Ang-(17)/MasR axis activation further resulted in reduction of astrogliosis as indicated by decreased intensity of NFKB and dwindled expression of its downstream NLRP3 cascade signaling molecules. These results were confirmed by using a selective inhibitor of ACE-2, MLN-4760, which reversed the protective effects of ACE2 activation by DIZE. Subsequently, treatment with DIZE in STZ induced rat model of AD prevented cognitive impairment and progression of amyloid pathology. Therefore, the involvement of ACE2/Ang-(17)/Mas axis suggests that it could be further explored as a potential pathway in $A D$, owing to its inhibitory effect on inflammation/astrogliosis and restoring cognitive functions.

\section{Highlights}

1. DIZE treatment improved spatial learning and memory impairment in STZ lesioned SD rats.

2. Activation of ACE2/ANG-(1-7)/Mas receptor Axis reduced NLRP3 inflammasome mediated neuroinflammation in STZ lesioned SD rats.

3. Activation of ACE2/ANG-(1-7)/Mas Axis downregulated glial activation.

4. ACE2/ANG-(1-7)/Mas Axis activation improved mitochondrial functionality by ablating $\mathrm{Ca}^{2+}$ influx and reduced MMP.

\section{Introduction}

Alzheimer's disease (AD) is a progressive neurodegenerative disorder accounting for 60 - $80 \%$ of all worldwide dementia cases [1]. It is characterized by a decline in learning and cognition, increased amyloid $\beta$ burden, tau hyperphosphorylation, altered neurotransmitter level, reduced neutrophils and synaptotoxicity that finally leads to neural atrophy $[2,3]$. Neuroinflammation is a primary barrier that protects the brain by abolishing or restraining varied pathogens [4]. The released inflammatory mediators can have protective effects by regulating tissue repair and clearing out cellular debris [5]. The neuroinflammatory response is arbitrated by glial cells (astrocytes, microglia), neurons, mast cells, T-cells, 
neutrophils, and inflammatory signals released from these cells [6]. Unlike other cells of the body, once the neuronal cells get damaged or degenerated, they fail to regenerate in the CNS [7]. Apart from transgenic models, Studies revealed that intracerebroventricular (ICV) streptozotocin (STZ) induced preclinical sporadic Alzheimer's disease (SAD) model leading to cognitive deficits along with reduced cholinergic neurotransmitter level, enhanced insulin resistance, altered glucose metabolism centrally leading to generation of plaques, oxidative stress and glial cell activation in both mice and rats models [8-11]. Another resemblance to AD patient is the enhanced reactive oxygen species (ROS) generation that leads to mitochondrial anomaly ultimately causing neurodegeneration [12-14]. There is no cure available yet for $A D$, while drug therapy for the disease is still in its infancy and has only been shown to improve patient's quality of life at, prescribed dosages regimen and stage of the disease [15]. This underlines the fact that complete understanding of $A D$ pathophysiology is lacking.

A vast body of evidence have suggested the involvement of renin-angiotensin system (RAS) i.e. Angiotensin Converting Enzyme / Angiotensin II / /Angiotensin Receptor Type-1 (ACE/Ang II/AT1R) axis in $A D$ progression [16]. Angiotensin II contributes to the development of $A D$ and causes, enhanced $\beta-$ secretase activity and amyloid- $\beta$ precursor protein, elevation in oxidative stress and neuroinflammation, reduced cerebral blood flow, and cognitive impairment [17]. O'Connor and coworkers reported that enhanced generation of Ang II, due to astrocyte activation, leads to neuroinflammation and neurodegeneration [18]. Another study revealed that oral ingestion of Perindopril (an ACE inhibitor) improved cognitive memory via NFKB downregulation in SHRs, suggesting that decreasing level of Ang II was neuroprotective [19]. These studies strengthened the findings of Bartus et al. (1982) and Barnes et al. (1992), which showed decreased acetylcholine (Ach) level in the brain with respect to increased angiotensin levels $[20,21]$. Clinical as well as preclinical studies have revealed that RAS inhibition protect against memory impairment, cholinergic dysfunction, oxidative stress, and $\beta$-amyloid deposition [22-25]. RAS triggers glial cells activation that leads to ROS generation and release of inflammatory mediators [26].

The aforementioned discussion shows that activation of ACE/Ang II/AT1R impinges on CNS and results in neuroinflammatory changes. However, the deleterious effect of ACE/Ang II/AT1R is countered by another axis of RAS, that is Angiotensin converting enzyme2/Angiotensin (1-7)/ Mas Receptor (ACE2/Ang-(1-7)/MasR) axis which is an important component of the brain. The presence of ACE2 has been observed in diverse brain areas and cell types, including neurons [27], astrocytes [28], and endothelial and smooth muscle cells of cerebral arteries [29]. ACE2 cleaves Ang II to produce Ang (1-7) independently. The Ang (1-7) is found in different brain regions including the hypothalamus, cerebellar cortex, hippocampus, substantia nigra, medulla oblongata, and amygdala [30]. It has been shown that ACE2 counters A $\beta$ mediated neurotoxic effect in APP transgenic mice as well as in vitro studies [31]. Xie and group has shown improvement in cognition deficits, that was mediated by Mas receptor in a rat model of cerebral ischemia [32, 33]. Furthermore, ICV Ang (1-7) administration abates infarction and neurodegeneration by reducing endothelin-1 in rodent MCAO model [34]. Jiang and colleagues (2012) have successfully established the relationship between decreased expression and activity of ACE2 in post mortem brain tissue and cerebrospinal fluid of AD patients. The role of oxidative stress has been reported 
in the progression of $A D$ and found to be an effective target in both preclinical and clinical studies. Increased NFKB expression and oxidative stress have been correlated with the decreased level of ACE2 and Ang-(1-7) [35, 33].

However, the role of ACE2 / Ang (1-7) / MasR axis in the progression and pathophysiology of AD in relation to inflammation is still unclear. Therefore, we hypothesized that there might be an association between activation of ACE2 / Ang (1-7) / MasR axis and inflammatory cascade involved in AD. Moreover, a USFDA approved small molecule and an ACE2 activator, Diminazene aceturate (DIZE), is generally prescribed for the treatment of animal trypanosomiasis [36]. Pharmacologically, DIZE activates the protective axis of RAS by activating ACE2 leading to generation of Ang (1-7). It is also found to be cardioprotective by inducing angiogenesis in rat model of pulmonary hypertension [37]. Furthermore, in the present study, DIZE owing to its ACE2 activating potency, has been harnessed to activate ACE2.

\section{Materials And Methods}

DIZE was purchased from Santa-Cruz Biotechnology (cat no. Sc-205651) and freshly prepared daily. STZ was procured from Calbiochem (catalog no. 572201). All other rats received equivalent volumes of vehicle (saline) injections.

A competitive ACE2 antagonist, MLN4760 was procured from Merck Millipore (CAS 305335-31-3). It shows high binding affinity towards ACE2 enzymatic active site and significantly alters the ACE2 protein conformation [38]. The MLN4760 was administered concomitantly with DIZE using a similar vehicle, at $10 \mu \mathrm{M}$ concentration. This dose was selected on the basis of previously done studies using MLN-4760 studies $[39,38]$. All other chemicals and reagents were of analytical grade.

\subsection{Cell culture and treatment}

Mouse neuroblastoma cell line (Neuro-2A/N2A cell) was procured from National Centre for Cell Sciences, Pune, India, and supplemented with DMEM encompassing $10 \% \mathrm{FBS}$ at $37^{\circ} \mathrm{C}$ in a controlled atmosphere ( $5 \% \mathrm{CO}_{2} / 95 \%$ air). STZ was freshly prepared in serum free media at the time of administration in serumfree media. N2A cells were incubated with STZ $(2.5 \mathrm{mM}$, optimized using MTT assay; Supplementary Fig. $1 A$ and $B)[40,41]$ in absence or presence of DIZE $(25 \mu \mathrm{M}$, lowest effect dose standardized using MTT assay; Supplementary Fig. 1C and D) and DIZE alone for $24 \mathrm{~h}$. Cells were treated with DIZE after 30 min of STZ addition.

\subsubsection{Primary Astrocyte culture}

Astrocyte culture media $(30 \mathrm{ml})$ was pre-warmed (DMEM F-12 $+10 \%$ heat-inactivated fetal bovine serum $+1 \%$ Penicillin/Streptomycin) to $37^{0} \mathrm{C}$. T-75 flask was coated with $10 \mathrm{ml}$ of poly-D-lysine (PDL) (50 $\mu \mathrm{g} / \mathrm{ml}$ ) dissolved in cell culture grade water and placed at $37{ }^{\circ} \mathrm{C}$ in $\mathrm{CO}_{2}$ incubator for $2 \mathrm{hr}$. For the dissection procedure, HBSS media was prepared and $\mathrm{pH}$ was adjusted between 7.2 to 7.4. Pups were sacrificed following the decapitation process and brain was isolated and minced under sterile conditions 
with the addition of HBSS buffer. After removing HBSS buffer, and 2.5\% trypsin was added for tissue dissociation and placed in incubator at $37^{\circ} \mathrm{C}$ for $30 \mathrm{~min}$. The mixture was centrifuged ( $5 \mathrm{~min}$ at $300 \mathrm{x} \mathrm{g}$ ) and the pellet was carefully collected. Tissue was triturated in astrocyte plating medium $(10 \mathrm{ml})$ with the help of a $1 \mathrm{ml}$ and $10 \mu \mathrm{l}$ pipette. The pellet was passed through a 70-micron filter to obtain single-cell suspension and the cells were subsequently plated in a flask. After achieving approximately $70-80 \%$ confluece the flasks were placed on an orbital shaker (180 rpm for $30 \mathrm{~min}$ ) to remove the supernatant containing microglia. To further remove oligodendrocyte precursor cells (OPC), fresh medium (20 ml) was added to the astrocyte culture and flask remained in shaking condition at $240 \mathrm{rpm}$ for $6 \mathrm{hr}$. Finally, the confluent astrocyte cell layer was washed twice with PBS and incubated with fresh medium in $\mathrm{CO}_{2}$ incubator at $37^{\circ} \mathrm{C}$ for further experimentation.

\subsubsection{Estimation of Ang-(1-7) level}

The Ang (1-7) level was estimated in isolated brain tissue of treated and untreated rats/N2A cells using conventional ELISA kit (Fine Test, China) according to the manufacturer's protocol. In brief, the evacuated brain tissue of treated and untreated rats/harvested N2A cells were homogenized in ice-cold PBS with $5 \%$ $(\mathrm{w} / \mathrm{v})$ protease inhibitor cocktail (Sigma) followed by sonication (10 secs; 20 cycles) using an ultrasonic processor (Heat Systems-Ultrasonic inc.) and centrifugation at $20,000 \mathrm{~g}(15 \mathrm{~min})$ at $4{ }^{0} \mathrm{C}$. The data was expressed in the terms of $\mathrm{pg} / \mathrm{ml}$ and $\mathrm{pg} / \mathrm{mg}$ for culture supernatants and brain tissue, respectively [42].

\section{2..1.3. Oxidative stress marker}

\subsubsection{Estimation of mitochondrial ROS}

Mitochondrial ROS was estimated using Mito SOX Red (Invitrogen, USA), which is a live-cell permeant that rapidly and selectively targets mitochondria [43]. Once in the mitochondria, Mito SOX Red reagent gets oxidized by superoxide and imparts red colored fluorescence (with excitation at $510 \mathrm{~nm}$ and emission at $580 \mathrm{~nm})$. N2A cells were seeded in 6-well plates $\left(2 \times 10^{5}\right.$ cells/well), and treated with STZ $(2.5 \mathrm{mM})$, with or without DIZE for $24 \mathrm{~h}$. After $24 \mathrm{~h}$ of treatment cells were incubated with $5 \mu \mathrm{M}$ Mito SOX Red for 10 min at $37{ }^{\circ} \mathrm{C}$, and washed twice with PBS., Fluorescence signal was detected using a laser system (FACS calibur; BD bioscience, USA) with $510 \mathrm{~nm}$ excitation and $580 \mathrm{~nm}$ emission filters.

\subsubsection{Estimation of reduced Glutathione (GSH) level}

Reduced glutathione was estimated by 5, 5-dithiobis (2-nitrobenzoicacid) [DTNB, Ellman's reagent that yields a yellow colored product. N2A cells were plated ( $4 \times 10^{5}$ cells/well). Following treatment, cells were scraped by adding $100 \mu \mathrm{l}$ of PBS (ice cold). Cells were lysed by ultra-sonication, and centrifuged at $10,000 \mathrm{~g}$ for $5 \mathrm{~min}$ at $4{ }^{0} \mathrm{C}$. Subsequently $10 \%$ trichloroacetic acid $(100 \mu \mathrm{l})$ was added to this lysate for protein precipitation and suspension was kept on ice for $1 \mathrm{hr}$. Samples were re-centrifuged at $5000 \mathrm{~g}$ for 5 min and supernatant was collected. Further supernatants $(75 \mu \mathrm{l})$ was mixed with $25 \mu \mathrm{l}$ of distilled water followed by $100 \mu \mathrm{l}$ of buffer and DTNB $(50 \mu \mathrm{l})$. Reaction mixture was incubated for $10 \mathrm{~min}$ and read at $412 \mathrm{~nm}$. [41]. 


\subsubsection{Acetylcholinesterase Activity Estimation}

AChE activity was estimated by the method described by Ellman et al. [44] with a few minor changes. After treatment, the cells were scraped and lysed in $0.1 \mathrm{M}$ sodium phosphate buffer (PB, pH 8.0) with Triton-X $100(0.1 \%)$ followed by centrifugation at $10,000 \times$ rpm for 20 min at $4{ }^{0} \mathrm{C}$ subsequently supernatant was mixed with $100 \mu \mathrm{M}$ of 5,5'-dithio-bis (2-nitrobenzoic acid (DTNB) and 0.1 M PB. After 10 min incubation at $37^{\circ} \mathrm{C}, 20 \mathrm{mM}$ acetylthiocholine iodide was added to initiate the enzymatic reaction. The enzymatic activity was measured at $412 \mathrm{~nm}$ for $2 \mathrm{~min}$ at a $15 \mathrm{sec}$ interval by spectrophotometer and specific activity of AChE was presented in $\mu$ moles / $\mathrm{min} / \mathrm{mg}$ of protein.

\subsubsection{Intracellular $\mathrm{Ca}^{2+}$ level estimation}

Intracellular $\mathrm{Ca}^{2+}$ level was studied using the manufacturer's protocol. In brief, N2A cells $\left(5 \times 10^{4}\right)$ were firstly incubated with $5 \mu \mathrm{M}$ Fluo4-AM at $37^{\circ} \mathrm{C}$ for $30 \mathrm{~min}$ in dark. Cells were washed with PBS to remove the extracellular Fluo4-AM and resuspended in PBS. The fluorescence signal was detected using a laser system (FACS calibur; BD bioscience, USA). An argon laser was used to excite Fluo4 at $494 \mathrm{~nm}$, and the emission was measured at $506 \mathrm{~nm}$. The fluorescence intensity for each sample was determined by using Cell Quest software (BD bioscience, USA)

\subsubsection{Mitochondrial membrane potential $(M M P / \Delta \Psi \mathrm{m})$ measurement}

Mitochondrial membrane potential $(\mathrm{MMP} / \Delta \Psi \mathrm{m})$ was assessed using mitochondrial membrane potential sensitive carbocyanine dye JC-1 (5,5',6,6'-tetrachloro-1,1',3,3'-tetraethyl benzamidazolocarbocyanine iodide, Sigma Aldrich, USA) in N2A cells $[45,46]$. After treatment cells were incubated with JC-1 dye (2.5 $\mu \mathrm{g} / \mathrm{ml}$, Sigma Aldrich, USA) in dark for $30 \mathrm{~min}$ at $37{ }^{\circ} \mathrm{C}$. After incubation, the cells were washed with PBS and Fluorescence signal was detected using a laser system (FACS calibur; BD bioscience, USA) with 488 $\mathrm{nm}$ excitation and $590 \mathrm{~nm}$ emission filters [47].

\subsubsection{Western blot analysis}

Freshly extracted treated cells and brain tissues were lysed using cold RIPA lysis buffer in the presence of $1 \mathrm{X}$ protein inhibitor cocktail (Sigma, USA) and dithiothreitol (DTT, $1 \mathrm{mM}$ ) as per manufacturer's instruction to extract protein. $[48,49]$. Protein was separated on 10-15\% SDS-PAGE subsequently transferred onto the PVDF membrane (Millipore, Bedford, MA, USA). The membrane was probed with bovine serum albumin (BSA, $5 \%$ ) for $2 \mathrm{hr}$ at room temperature and subsequently incubated overnight at $4{ }^{0} \mathrm{C}$ with primary antibodies; rabbit anti-ACE2 (1:1000, catalogue no.: AF5165; Affinity biotech Cincinnati, USA), rabbit antiMasR (1:500, catalogue no. NBP1-78444; Thermo fisher scientific, USA), rabbit anti-NFKB (1:500, catalogue no.: sc-109; Santa Cruz Biotechnology CA, USA), rabbit anti- NLRP3 (1:1000, catalogue no. DF7438; Affinity biotech Cincinnati, USA), rabbit anti-caspae-1 (1:1000, catalogue no. AB1871; Sigma Aldrich, USA), rabbit anti-IL-1 $\beta$ (1:1000, catalogue no. PA5-95455;Thermo fisher scientific, USA), mouse anti-Aß42 (1:1000, catalogue no. NBP2-13075; Novus Biologicals, LLC, USA), rabbit anti p- TAU (1:1000, catalogue no. NBP2-20574; Novus Biologicals, LLC, USA), rabbit anti-TAU (1:500, catalogue no. sc-32274; 
Santa Cruz Biotechnology CA, USA), mouse anti- $\beta$-actin (1:2000, catalogue no. A5316; Sigma Aldrich, USA). Following the incubation, the membrane was washed with washing buffer (pH 7.6, TBS, $0.1 \%$ Tween 20) and probed with horseradish peroxidase (HRP) conjugated secondary antibody (anti-mouse IgG/anti-rabbit IgG, 1:5000, GeNei, India) for $2 \mathrm{~h}$ at room temperature. Signal intensity was estimated by using ECL (enhanced chemiluminescence) Millipore MA, USA) and quantified by mylmage analysis software (Thermo Scientific, USA).

\subsubsection{Immunocytochemistry (ICC)}

ICC study was performed as per the protocol described earlier with minor modification [50]. Cells were incubated with primary antibodies; rabbit anti-ACE2 (1:1000, catalogue no.: AF5165; Cincinnati, USA), rabbit anti-MasR (1:500, catalogue no. NBP1-78444; Thermo fisher scientific, USA), rabbit anti-NFKB (1:200, catalogue no.: sc-109; Santa Cruz Biotechnology CA, USA), mouse anti-GFAP (1:500, catalogue no.: MAB360; Millipore, MA, USA) were incubated for 8-12 hr at $4{ }^{\circ} \mathrm{C}$. Subsequently the cells were kept with respective Alexa Fluor-conjugated secondary antibodies (1:400) for $1 \mathrm{hr}$. After washing with PBS, cells were mounted firmly on slides followed by counterstaining with DAPI (Sigma Aldrich, USA). Images were taken under Leica inverted fluorescent microscope (DMI 6000) equipped with a digital CCD camera (Leica, Wetzlar, Germany) and quantified by ImageJ software (NIH, USA).

\subsection{Animals}

Adult male Sprague-Dawley (SD) rats (180-200 g) were obtained from National Laboratory Animal Centre (NLAC) of Central Drug Research Institute, Lucknow India. It is well documented that estrogens impart many beneficial effects in the brain including enhanced neuronal viability and reduced $A \beta$ accumulation. It is also reported that mitochondria from young females are less vulnerable for $A \beta$ toxicity, generate lesser ROS, as well as release of lower apoptotic signals compared to those of males [51,52]. Therefore, the male SD rats were the choice of animals in the present investigation targeting STZ induced. Animals were kept in a pathogen-free cages (dimension $435 \times 290 \times 150 \mathrm{~mm}$ ) in groups of $n=3$ per cage and controlled environment condition ( $23-25^{\circ} \mathrm{C}$ and $60-65 \%$ humidity), under $12 \mathrm{hr}$ light/dark cycles along with free access to food (normal chow diet) and water. Experimental procedures were approved by institutional animal ethics committee and met the guidelines of Committee for the Purpose of Control and Supervision of Experiment on Animals (CPCSEA); (approval no. (IAEC/2019/55/REN).

\subsubsection{Streptozotocin administration and DIZE treatment}

\subsubsection{Stereotaxic injection of streptozotocin}

SD rats were anesthetized by intraperitoneal administration of pentobarbitone sodium ( $40 \mathrm{mg} / \mathrm{kg}$, SigmaAldrich USA). Rats were carefully mounted on stereotaxic apparatus (Stoelting Co. USA) and their ears were fixed with the ear bars in the apparatus frame. The skin on the skull was sterilized and a longitudinal cut was precisely made to expose the skull, followed by careful wiping for bregma visualization. Two small burr holes were made in skull laterally and STZ $(10 \mu \mathrm{l}$ of $1 \mathrm{mg} / \mathrm{kg}$ in artificial cerebrospinal fluid 
(aCSF) was infused in each lateral ventricles at following coordinates: $-0.8 \mathrm{~mm}$ anteroposterior (AP), \pm 1.5 mediolateral (ML), -3.6mm dorsoventrally (DV) measured from bregma (Hamilton company, Switzerland) at a flow rate of $0.5 \mu \mathrm{l} / \mathrm{min}$ [53-55]. Lingered the syringe at aforementioned place for some time to reduce seepage. Likewise, the control group was administered same amount of aCSF in each ventricle.

\subsubsection{DIZE treatment}

Animals were randomly divided into 5 groups with 6 rats in each group. Group I that served as control was stereotaxically administered with $10 \mu \mathrm{l}$ of aCSF in each lateral ventricle (Box:1). The rats of group II (Neurotoxin) were stereotaxically administered with $10 \mu \mathrm{l}$ of STZ $(1 \mathrm{mg} / \mathrm{kg})$ in each ventricle. Group III and IV were together considered as the treatment group in which rats were treated with different doses of DIZE (10 mg/kg and $15 \mathrm{mg} / \mathrm{kg}$, i.p.) respectively 3-day post STZ administration for 21 days [16, 56-58]. The group V was treated with $15 \mathrm{mg} / \mathrm{kg}$ (i.p.) of DIZE for 21 days and served as per se group. Doses of 10 and $15 \mathrm{mg} / \mathrm{kg}$ were equally effective in improving memory functions (refer to section 3.2) with no effect on hemodynamic parameters (Supplementary Fig. 3). For subsequent in vivo experimentation, a minimum effective dose (10 mg/kg, i.p.) of DIZE was used.

\subsubsection{Behavioral parameter}

\subsubsection{Morris water maze test}

Morris water maze test was performed to assess the spatial learning and memory after DIZE treatment according to a previously published protocol $[59,54,55]$. The test was executed using a round pool (132 $\mathrm{cm} \otimes 75 \mathrm{~cm}$ ) having a platform submerged below the water meniscus and maintained at a temperature of $25 \pm 0.5^{\circ} \mathrm{C}$. Spatial and learning memory performance was conducted on day $18-20$ post DIZE treatment accompanied by probe trial on day 21 . On day 1 rats were allowed to swim in pool and the trial ended either by animal finds the platform or trial ends $(2 \mathrm{~min})$. Similarly, trials were conducted on day 2 and day 3 for proper acquisition of memory, and escape latency was calculated. On day 21 Probe trial was done in which the platform was removed and animal was allowed to swim for 1 minute. Data was recorded and analyzed using Anymaze software.

\subsubsection{Acetylcholine level estimation}

Acetylcholine level in brain tissue of treated and untreated rats was measured by using LC-MS/MS (ABSciex 4000, Toronto, Canada) equipped with an API electro-spray ionization (ESI) source. The instrument and compound parameters were optimized and set as follows: curtain gas, auxillary gas, and collision gas, were set at 30,35 , and 30 and declustering potential (DP), collision energy (CE), entrance potential (EP), and collision exit potential (CXP) were set at 135, 12, 10 and $30 \mathrm{~V}$. respectively. The ion spray voltage was set at $5500 \mathrm{~V}$ and zero air was used as source gas whilst the nitrogen was used as both curtain and collision gas. The mass spectrometer was operated at ESI positive ion mode and the ions were detected in the multiple reaction monitoring (MRM) mode, monitoring the transition of $\mathrm{m} / \mathrm{z}$ 146.20 precursor ion $[\mathrm{M}+\mathrm{H}]^{+}$to the $\mathrm{m} / \mathrm{z}$ 87.10. Separation was done through phenomenex Luna HILIC (3 
$\mu \mathrm{m}, 150 \times 4.6 \mathrm{~mm}$ ) column with a mobile phase consisting of acidified acetonitrile: $0.1 \%$ formic acid in the ratio of $90: 10(\mathrm{v} / \mathrm{v})$ at a flow rate of $0.5 \mathrm{ml} / \mathrm{min}$. Data acquisition and quantitation were performed using analyst software version 1.4.1 (Applied Biosystems, MDS Sciex Toronto, Canada).

For extraction of acetylcholine from brain tissue, a simple protein precipitation technique was followed as described in previous literature [60]. In brief, cold acetonitrile (extracting solvent) was added to the homogenized brain tissue (3:1). The mixture was vortexed (10 min) and further centrifuged at 10,000 rpm for $10 \mathrm{~min}$. Supernatant was separated and injected into column for LC-MS/MS analysis.

\subsubsection{Immunohistochemistry}

Rats were euthanized using high dose of sodium pentobarbital (50 mg/kg, i.p.) followed by perfusion with ice-cold paraformaldehyde (PFA, 4\%). The whole brain was fixed by preserving in PFA overnight at 4 ${ }^{0} \mathrm{C}$ and dehydrated serially with varying concentrations of sucrose $(10 \%, 20 \%$, and $30 \%)$ for $24 \mathrm{hr}$ each. Free-floating slices across the cortex and hippocampus ( $30 \mu \mathrm{m}$ thick) were treated with primary antibody, mouse anti-GFAP (1:500, Millipore, CA, USA)as mentioned in our prior publication [49]. Slices were firmly fixed on slides and counterstained with DAPI (Sigma Aldrich, USA). Fluorescent images were collected using Leica inverted fluorescence microscope (DMI 6000, Leica, Wetzlar, Germany) and quantified by Image J software (NIH, USA).

\subsection{Statistical Analysis}

All data were expressed as mean \pm SEM and statistical analysis was done by using Graph Pad Prism software (San Diego, CA, USA) by applying One way/two-way analysis of variance (ANOVA) followed by bonferroni post hoc test and $\mathrm{P}<0.05$ was considered as statistically significant.

\section{Results}

\subsection{Activation of ACE2/Ang-(1-7)/MasR axis with DIZE treatment}

N2A cells were pretreated with DIZE followed by exposure to STZ for examining the involvement of ACE2/Ang-(1-7)/MasR axis in neuroinflammation. Immunoblotting result revealed comparatively low ACE2 and MasR expression after STZ treatment (Fig. 1A). The treatment of N2A cells with DIZE ( $25 \mu \mathrm{M}$; Supplementary Fig. $1 C$ and D) increased cellular ACE2 (Fig. 1B, p<0.01, F $(3,8)=18.69$ ) and MasR (Fig. $1 C, p<0.01, F(3,4)=28.32)$ expression in STZ treated N2Acells. DIZE per se treatment showed no change as compared to control.

For validation of above results, N2A cells were exposed to MLN-4760 for $24 \mathrm{hr}$ which resulted in a significant dose-dependent decrease of cell viability in comparison to the STZ+DIZE treated cells (Supplementary Fig. 2). Protective effect was checked upon treatment with DIZE ( $25 \mu \mathrm{M})$ along with MLN-4760 $(10 \mu \mathrm{M})$, and immunoblotting was performed (Fig. 1D). Treated cells showed enhanced expression of ACE2 (Fig. 1E, p<0.01, F $(3,8)=16.92$ ) and MasR (Fig. $1 F, p<0.05, F(3,7)=12.20)$. On the 
contrary, MLN-4760 treatment in STZ+DIZE treated cells reduced the expression of ACE2 and MasR, suggesting the subsequent activation of ACE2/Ang-(1-7)/MasR axis on DIZE treatment.

\subsection{Evaluation of the role of Ang-(1-7) in neuroprotective effects of ACE2/Ang-(1-7)/MasR axis activation}

The involvement of Ang (1-7) in mediating the cytoprotective effects of DIZE against STZ induced toxicity was also investigated. The levels of active peptide Ang-(1-7) comparatively decreased following STZ treatment (Fig. 2A, p<0.01). However, cells treated with DIZE had higher level of Ang-(1-7) (Fig. 2A, $p<0.05$, $F(3,4)=30.62)$ than cells treated with STZ but DIZE per se treatment did not alter the levels of Ang- $(1-7)$. Antagonizing this effect by MLN-4760 significantly reduced the Ang-(1-7) level (Fig. $2 B, p<0.01, F(3,4)=$ 141.9) after the STZ and DIZE treatment. Similar results of modulation of Ang (1-7) level in vivo were observed in both brain regions showing increased levels of Ang (1-7) in STZ administered rats upon DIZE treatment (Fig. $2 \mathrm{C}, \mathrm{p}<0.01, \mathrm{~F}(3,8)=118.92)$.

\subsection{Activation of ACE2/Ang-(1-7)/MasR axis ameliorate oxidative stress burden and mitochondrial abnormalities}

To investigate the influence of ACE2/Ang-(1-7)/MasR axis activation on oxidative stress burden, intracellular ROS was measured by FACS analysis (Fig. 3A). Treatment of N2A cells with STZ enhanced total ROS, which was decreased owing to DIZE induced activation of ACE2/Ang-(1-7)/MasR axis (Fig. 3B, $p<0.001, F(3,8)=81.75)$. STZ treatment also reduced the glutathione level which was reversed by treatment with DIZE (Fig. 3C, p<0.01)

For determination of potential role of ACE2/Ang-(1-7)/MasR axis activation on mitochondrial functionality, mitochondrial ROS (mtROS) was estimated in N2A cells by FACS analysis. As shown in Fig. 3D STZ treatment for $24 \mathrm{hr}$ augmented mtROS generation whereas treatment with DIZE $(25 \mu \mathrm{M})$ inhibited this effect in N2A cells (Fig. 3E, $p<0.01, F(3,8)=31.48)$.

JC-1 was used to detect the mitochondrial membrane potential (MMP/ $\triangle \Psi \mathrm{m})$ to evaluate the effect of ACE2/Ang-(1-7)/MasR axis activation on mitochondrial functionality in N2A cells (Fig. 3F). Flow cytometric analysis showed reduction in MMP in STZ treated N2A cells (Fig. 3G, $p<0.001, F(3,8)=327.4$ ), which was inhibited by treatment with DIZE. The DIZE alone exposed cells didn't show any significant modulation in MMP.

Intracellular calcium ions $\left(\mathrm{Ca}^{2+}\right)$, essential to mitochondrial function, were estimated using Fluo-4AM kit. STZ exposure to N2A cells increased $\mathrm{Ca}^{2+}$ level, while treatment with DIZE abolished the increase in $\mathrm{Ca}^{2+}$ level $(\mathrm{Fig} .3 \mathrm{H}-\mathrm{I}, \mathrm{p}<0.001, \mathrm{~F}(\mathbf{3}, \mathbf{8})=\mathbf{7 1 . 1 3})$ DIZE per se group showed no difference from untreated cells.

\subsection{ACE2/Ang-(1-7)/MasR axis activation down regulates NLRP3 inflammasome mediated neuroinflammation}

To determine mechanisms underpinning the induction of neuroinflammation, immunocytochemical analysis (Fig. 4A) was performed to evaluate the effect of activation of ACE2/Ang-(1-7)/MasR axis by 
DIZE on NF-KB p65. NF-kB activation by STZ upregulated p65 protein expression in N2A cells which was inhibited by DIZE treatment (Fig. 4B, $p<0.001, F(3,35)=601.1$ ) at $24 \mathrm{hr}$. DIZE per se treated cells showed diminished expression of NF-KB p65 similar control cells (Fig. 4B, p>0.05).

Further we checked NLRP3 inflammasome expression downstream to activation of priming signals in vitro (Fig. 4C), STZ exposed N2A cells were treated with or without DIZE (25 $\mathrm{MM})$ for $24 \mathrm{hr}$. Western blotting showed that STZ treatment increased levels of NLRP3, caspase-1 and IL-1 $\beta$ (Fig. 4D-F). Subsequent DIZE treatment reduced the levels of NLRP3 (Fig. 4D, $p<0.01, F(3,8)=9.193$ ), caspase-1 (Fig. $4 E, p<0.05, F(3,8)=7.26)$ and IL-1 $\beta(F i g .4 F, p<0.05, F(3,8)=10.44)$ in N2A cells. Treatment with DIZE per se did not alter the expression of NLRP3, caspase-1 and IL-1 $\beta$ (Fig. 4D-F).

To delve deeper into mechanism of the protective effect of DIZE in STZ exposed N2A cells, cells were treated with DIZE $(25 \mu \mathrm{M})$ along with MLN-4760 $(10 \mu \mathrm{M})$, and immunoblotting was performed (Fig. 4G). Decreased expression of NLRP3, caspase-1 and IL-1 $\beta$ was observed after DIZE treatment in STZ exposed N2A cells (Fig. $4 \mathrm{H}-\mathrm{J}$ ). In contrast, MLN-4760 treatment in cells reversed the effect of DIZE by increasing of expression of NLRP3 (Fig. 4H, p<0.01, F (3,8) = 16.85), caspase-1 (Fig. $4 \mathrm{I}, \mathrm{p}<0.05, \mathrm{~F}(\mathbf{3}, \mathbf{8})=\mathbf{3 8 . 4 7}$ ) and IL-1 $\beta$ (Fig. $4 \mathrm{~J}, \mathrm{p}<0.05, \mathrm{~F}(3,8)=11.29)$ suggesting involvement of ACE2/Ang-(1-7)/Mas receptor axis in the regulation of NLRP3 inflammasome activation.

We next examined the effect of ACE2/Ang-(1-7)/Mas receptor axis activation on NLRP3 inflammasome modulation in vivo. Immunoblotting study in both cortex (Fig. 4K) and hippocampus (Fig. 4L) brain regions suggested that administering DIZE (10 mg/kg, i.p.) in ICV STZ treated rats reduced the expression of NLRP3 (Fig. 4M, p<0.001, p<0.01, F (3,16) = 24.62), caspase-1 (Fig. $4 \mathrm{~N}, \mathrm{p}<0.05, \mathrm{p}<0.05, \mathrm{~F}(3,8)=40.73$ ) and IL-1 $\beta$ (Fig. 4O, p<0.01, p<0.05, F (3,12) = 17.98). Therefore, activation of ACE2/Ang- $(1-7) /$ Mas receptor axis might protect against NLRP3 inflammasome mediated neuroinflammation

\subsection{ACE2/Ang-(1-7)/MasR axis activation reduces astrogliosis after STZ treatment}

GFAP immunostaining was performed to examine the effect of DIZE treatment on astrogliosis due to STZ administration in the cortex (Fig. 5A) and hippocampal (Fig. 5B) brain sections. We observed significantly enhanced $\mathrm{GFAP}^{+}$cells in both cortex and hippocampus brain regions in STZ lesioned rats whilst treatment with DIZE in STZ lesioned rats reduced GFAP ${ }^{+}$cells in both the brain regions (Fig. $5 C, p<0.001$, $F(3,39=43.52)$ ), suggesting that DIZE attenuates reactive astrogliosis alleviating STZ induced neurotoxicity.

In addition to enhanced astrogliosis in vivo, we examined the possible effect of activation of ACE2/Ang(1-7)/MasR axis upon enhanced astrogliosis by double immunostaining using primary astrocytes. We observed decreased expression of ACE2 (Fig. 5D-F) and MasR (Fig. 5G-I) in primary astrocytes showing increased expression of GFAP as seen in STZ administered group. On activation of ACE2/Ang-(17)/MasR axis with DIZE after STZ treatment, cells showed enhanced expression of ACE2 (Fig. 5F, $\mathrm{p}<0.001, \mathrm{~F}(3,17)=22.53)$ and MasR $(F i g .5 \mathrm{I}, \mathrm{p}<0.001, \mathrm{~F}(3,17)=22.52)$ while a decreased GFAP expression. 


\subsection{ACE2/Ang-(1-7)/MasR activation rescued spatial recognition memory deficits}

Reports have established that ICV STZ administration leads to cognitive loss [55]. Morris water maze test was employed to assess spatial learning and memory task with two doses of DIZE (10 and $15 \mathrm{mg} / \mathrm{kg}$, i.p.) based on previous work $[16,58,61]$. Upon ICV STZ administration, there was negligible improvement in escape latency time in the 2nd and 3rd session as compared to their respective 1 st session indicating a deficit in spatial learning. Treatment with DIZE comparatively decreased the escape latency time (Fig. 6A, $p<0.001, F(4,87)=57.19)$ and path length (Fig. 6B, p<0.001, F (4,87) = 9.84) in the 2nd and 3rd session, indicating reversal of spatial learning deficit in ICV STZ treated rats. However, we observed no significant change in swim speed (Fig. $6 \mathrm{C}, \mathrm{F}(4,86)=\mathbf{2 . 2 1}$ ) of rats, suggesting that the aforementioned alteration depends upon STZ induced neuronal degeneration. A reduced time spent in the target quadrant in the ICV STZ group indicated a deficit in retention memory, which was reversed by DIZE treatment (Fig. 6D, $p<0.001)$. Representative track plot of the path traced by an animal of each group during one of the trials in 3rd session (Fig. 6E) indicated that ICV STZ treated animals took comparatively longer time to reach the platform; suggesting that DIZE a significantly attenuated $\mathrm{g}$ spatial learning and caused retention deficits in STZ lesioned rats. Doses of 10 and $15 \mathrm{mg} / \mathrm{kg}$ were equally effective in improving memory functions with no effect on hemodynamic parameters (Supplementary Fig. 3). For subsequent in vivo experimentation, a minimum effective dose $(10 \mathrm{mg} / \mathrm{kg}$, i.p.) of DIZE was used.

\subsection{Reduced ACE2/Ang-(1-7)/MasR activation in brain of ICV STZ induced A $\beta$ load and tau pathology}

To further understand the role of ACE2/Ang-(1-7)/MasR activation on A $\beta$ production and tau hyperphosphorylation in both cortex (Fig. 7A) and hippocampus (Fig. 7B) brain regions, we performed western blotting in ICV STZ administered rats. A significant increase in the expression of A $\beta-42$ level (Fig. $7 C, p<0.05, p<0.01, F(3,12=11.49)$ ) and tau hyperphosphorylation (Fig. $7 D, p<0.001, p<0.01, F(3,16)=$ 58.16) in both the brain regions of ICV STZ treated rats was observed. Treatment with DIZE decreased augmentation in these proteins of amyloid pathology.

\subsection{ACE2/Ang-(1-7)/MasR axis activation improved cholinergic activity}

The effect of ACE2/Ang- (1-7)/MasR axis activation on AChE enzyme activity was determined. STZ treated N2A cells showed increased AChE activity (Fig. 8A, p<0.001) whereas treatment with DIZE decreased AChE in the STZ+DIZE $(25 \mu \mathrm{M})$ treated N2A cells (Fig. $8 \mathrm{~A}, \mathrm{p}<0.05, \mathrm{~F}(\mathbf{3}, \mathbf{8})=\mathbf{1 0 . 9 2}$ ), however, no difference (Fig. 8A) was detected in the DIZE per se treated cells.

ACh levels in the cortex and hippocampal brain region of STZ lesioned rats decreased as detected by LCMS/MS (ABSciex 4000, Toronto, Canada) equipped with an API electro-spray ionization (ESI) source. ACE2/Ang-(1-7)/MasR axis activation by treatment with DIZE (10 mg/kg, i.p.) increased (Fig. 8B, p<0.001, $F(3,40)=48.71)$ ACh level in STZ treated rats in both brain regions however, no significant difference (Fig. 8B) was detected between the DIZE per se treated rats as compared to aCSF treated rats.

\section{Discussion}


The ACE2/Ang-(1-7)/MasR axis is known to counter the ACE /Ang II/AT1 receptor axis and in brain it acts as a neuroprotective component by reducing cerebral infarct size and neuronal apoptosis [62]. However, the potential role of ACE2/Ang-(1-7)/MasR axis in STZ induced AD model has not been yet elucidated. Our study demonstrates that activation of ACE2/Ang-(1-7)/MasR axis improves cognitive decline and memory loss through inhibition of neuroinflammatory cascades.

The ACE/Ang II/AT1R axis of RAS activation is traditionally known for progression of inflammatory changes in brain. Moreover, activation of another axis, ACE2/Ang-(1-7)/MasR of RAS could play a vital role in modulation of neuroinflammatory alterations as has been demonstrated in the present study using an ACE2 activator (DIZE) and its inhibitor (MLN-4760). The present investigation showed that STZ caused neuroinflammation which induced down regulation of ACE2/Ang-(1-7)/MasR axis that was significantly upregulated after exposure of DIZE in neuronal cells. The results were further strengthened with the application of an ACE2/Ang-(1-7)/MasR axis inhibitor where a remarkable decline in protein expression of ACE2 and MasR was observed along with a notable reduction in Ang-(1-7) levels. Previous studies have also demonstrated that ACE2 activation by DIZE restored MasR expression and Ang-(1-7) content in brain thereby exhibiting protection against neuroinflammatory changes during neurological deficits $[63,31,58]$. Consistent with the association between oxidative stress and neuroinflammation, we noticed generation of ROS and suppressed reduced glutathione, post STZ induced inflammation which was further balanced after exposure of DIZE to neuronal cells. Similarly, previous literature has also reported increased free radical generation after STZ induced neuronal inflammation as evidenced in both in vitro and in vivo experimental conditions [64]. Glutathione, a naturally-existing antioxidant in the brain/other body cells, scavenges the generated free radicals thus providing cellular protection. Thereby, the up surged levels of GSH after DIZE exposure to inflammatory cells manifests the protective efficacy of ACE2 activation in neuroinflammation that is in line with previous finding [65].

Further, oxidative stress burden owing to inflammatory responses relates to mitochondrial dysfunction too. The higher comparison quotient of JC-1 agglomerates to monomers signifies increased membrane depolarization in cells indicating optimum health of the concerned cells. This correlation, mediated by mitochondrial ROS functioning as a second messenger molecule, suggests the role of mtROS in neurodegeneration. However, negligible work has focused on the effect of regulation of mitochondrial functionality targeting the ACE2/Ang-(1-7)/MasR axis. A recent report suggested that ACE2 exerts a conspicuous effect on intramuscular fat regulation by enhancing endoplasmic reticulum and mitochondrial functionality. Likewise, we observed an enhanced $\Delta \psi_{\mathrm{m}}$ in STZ induced neuroinflammatory cells which was significantly abated by DIZE treatment [66-68]. Mitochondrial dysfunction further leads to $\mathrm{Ca}^{2+}$ imbalance through impaired regulation of calcium channels in neurological deficits. We observed augmented $\mathrm{Ca}^{2+}$ levels due to STZ exposure that was remarkably subsided after DIZE treatment, suggesting the role of ACE2/Ang-(1-7)/MasR axis activation in synchronizing the calcium channels during neurodegeneration and neuroinflammation, which is in line with studies suggesting an enhanced level of intracellular $\mathrm{Ca}^{2+}$ in neurons during $A D$ progression [69] 
Recently, several investigations have reported ROS mediated upregulation of NF-KB/ NLRP3 signaling as a pathological hallmark for neuroinflammation/neurodegenerative diseases. Furthermore, several emerging evidences have reported that ROS induced NF-KB activation directly initiating NLRP3 inflammasome cascade $[70,71]$. In the present study, we observed that STZ induced neuroinflammation and neurodegeneration was directly correlated with increased production of NF-KB/ NLRP3 as evident with enhanced protein expression of NF-KB/NLRP3 and its downstream signaling molecules in neuronal cells. However, activation of ACE2/Ang-(1-7)/MasR axis after DIZE treatment averted ROS mediated NFKB/ NLRP3 activation in neuronal cells. Likewise, a previous study has shown ACE2/Ang-(1-7)/Mas receptor axis mediated protection against NF-KB in STZ treated N2A cells which was mediated via activation of the MyD88 adaptor protein [72]. We found that ACE2/Ang-(1-7)/Mas receptor axis activation by DIZE inhibited NLRP3 inflammasome and subsequently led to caspase-1 deactivation and marked decrease in IL-1 $\beta$ expression both in in vitro and in vivo. Furthermore, blocking ACE2 activity by MLN-4760 activated the NLRP3 inflammasome pathway mediated by enhanced expression of caspase-1 and IL-1 $\beta$ consequently. Our finding is backed by a previous report indicating the inhibitory effect of Ang (1-7) on Angll-induced NLRP3 inflammasome activation regulated via Spry1 in lung fibroblasts[73].

In the present study an increased expression of GFAP has been observed in both the cortex and hippocampal brain regions of ICV-STZ induced neurodegeneration in rats. On contrary, the activation of ACE2/Ang-(1-7)/Mas receptor axis by DIZE treatment notably reduced the activation of GFAP in both cortex and hippocampal brain regions of ICV-STZ induced neurodegeneration in rats. For the affirmation of this phenomenon, we performed colocalization of GFAP with ACE2/MasR using primary astrocytic culture and observed enhanced intensity of ACE-2/MasR after DIZE treatment. The aforementioned findings are in accordance with previous literature in which an increase in GFAP has been observed in a triple transgenic ( $3 x-T g)$ mouse model of $A D$ followed by loss of glial somata volume [74] in the hippocampus indicating an interlink between astrogliosis and $A D$ pathogenesis.

Neuroinflammation, one of the major consequences of central nervous system (CNS) response to insults such as a $A \beta$ burden, tau hyperphosphorylation [75], gliosis (reviewed in [76]) and trauma [77], which are known mediators of the neuroinflammatory response that occurs following neurodegeneration. Emerging evidence suggest the relationship between accumulation of A $\beta$ in glial cells and NLRP3 inflammasome activation resulting in release of IL-1 $\beta$ in experimental $A D$ model [72]. In support, we have assessed the protective role of ACE2/Ang-(1-7)/Mas receptor axis in cognitive impairment in a rat model of STZ induced AD-like phenotype, as demonstrated by a decreased escape latency time after DIZE treatment in STZ lesioned rats on day $2 \mathrm{nd}$ and $3 \mathrm{rd}$ session compared the $1 \mathrm{st}$ session. Our results suggested higher time spent in the target quadrant after DIZE treatment as compared to STZ administration indicating improvement in spatial cognition following DIZE treatment, which could be a consequence of the attenuated synaptic and neuronal loss in brain. It was supported by studies which showed that DIZE attenuated the cognitive impairment in transgenic mouse model $[78,58]$. Further, the hallmark pathological markers were also investigated for their expression after DIZE treatment in ICV-STZ induced AD like phenotypic model. Expectedly, increased expression of $A \beta-42$ and p-tau was observed after STZ administration in rats. This was reversed after activation of ACE2/Ang-(1-7)/Mas receptor axis in a 
significant manner. The findings suggest the plausible involvement of activation of ACE2/Ang-(1-7)/Mas receptor axis against ICV-STZ induced AD pathology.

Lastly, we also observed a significant increase in AChE activity, a rate-limiting enzyme after STZ exposure which was diminished after DIZE treatment suggesting that activation of ACE2/Ang-(1-7)/Mas receptor axis might have a beneficial effect against STZ induced neurotoxicity. A supporting study showed enhanced parasympathetic modulation by DIZE, that was mediated by inhibition of AChE [79]. ACh is considered to be an anti-inflammatory molecule and has also been correlated with enhanced AChE activity leading to increased ILs and other inflammatory markers [80]. Moreover, our study further showed enhanced acetylcholine level after activation of the ACE2/Ang-(1-7)/Mas receptor axis by DIZE treatment in STZ lesioned rats. Acetylcholine neurotransmitter play a vital role in cognitive functions Hence, a marked decrease in cholinergic activity might lead to aging-related disorders [81]. A study showed that Ang (1-7) restored acetylcholine mediated vasodilation in high salt fed animals [82].

In summary, we demonstrated the protective effect of ACE2/Ang-(1-7)/Mas receptor axis activation against STZ induced neurodegenerative model through the regulation of canonical and non-canonical signaling as a consequence of NLRP3 inflammasome activation. Our study, in congruence with previous studies establish ACE2/Ang-(1-7)/Mas receptor axis as a protective axis in neurodegeneration.

\section{Abbreviations}

ACE2 Angiotensin converting enzyme2

aCSF artificial Cerebrospinal fluid

AD Alzheimer's Disease

A $\beta$ Amyloid-beta

DIZE Diminazene aceturate

GFAP Glial fibrillary acidic protein

GSH Glutathione

ICV Intracerebroventricular

$\operatorname{MMP}(\Delta \Psi \mathrm{m})$ Mitochondrial membrane potential

MWM Morris water maze

NFT Neurofibrillary tangle

ROS Reactive oxygen species 


\section{Declarations}

\subsection{Funding}

The study was supported by a financial grant from the Department of Biotechnology (DBT-

BT/PR27480/MED/122/138/2018). The authors are sincerely grateful to Director, CSIR-CDRI for continuous encouragement and support. Virendra Tiwari, Jitendra Singh and Swati Chaturvedi are supported by a research fellowship from CSIR, New Delhi, India. Meanwhile, Shivangi Gupta is supported by a research fellowship from DST, New Delhi, India. Priya Tiwari is supported by a research fellowship from University Grants Commission (UGC), New Delhi, India.

\subsection{Acknowledgment}

The authors would also like to offer their sincere thanks to Mr. M. L. Vishwakarma for the provision of FACS analysis of samples during the whole study.

\subsection{Data availability}

Data supporting the findings of this manuscript are available from the corresponding authors upon reasonable request.

\subsection{Code availability}

Not applicable.

\subsection{Authors' Information}

Virendra Tiwari ${ }^{1,2}$, Jitendra Singh ${ }^{1}$, Priya Tiwari ${ }^{2,3}$, Swati Chaturvedi ${ }^{2,4}$, Shivangi Gupta ${ }^{1,2}$, Akanksha Mishra ${ }^{1,5}$, Sonu Singh ${ }^{1,6}$, Muhammad Wahajuddin ${ }^{2,4}$, Kashif Hanif ${ }^{2,3}$, Shubha Shukla ${ }^{1,2}$

${ }^{1}$ Division of Neuroscience and Ageing biology, CSIR- Central Drug Research Institute, Lucknow-226031, (U.P.), India.

${ }^{2}$ Academy of Scientific and Innovative Research (AcSIR), Ghaziabad-201002, India.

${ }^{3}$ Division of Pharmacology, CSIR- Central Drug Research Institute, Lucknow-226031, (U.P.), India.

${ }^{4}$ Division of Pharmaceutics and Pharmacokinetics, CSIR - Central Drug Research Institute, Lucknow226031, (U.P.), India.

${ }^{5}$ Department of Cell Biology and Anatomy, New York Medical College, Valhalla, NY 01595, USA. 
${ }^{6}$ Department of Neuroscience, School of Medicine, University of Connecticut (Uconn) Health Center, 263 Farmington Avenue, L-4078, Farmington, CT 06030, USA.

\subsubsection{Contributions}

VT wrote the original draft and performed most of the experiment, JS conducted culture related work, SC performed LC/MS and MW supervised LC/MS related experiment, SG performed western blotting, PT performed NIBP and ELISA related work, AM and SS helped in analysis of data and writing the manuscript, $\mathrm{KH}$ and SS conceptualized the idea, supervised and edited the manuscript. All authors reviewed the results and approved the final version of the manuscript.

\subsubsection{Corresponding authors}

Correspondence to Shubha Shukla

\subsection{Ethics declarations}

\subsubsection{Conflict of interest}

The authors declare that they have no conflict of interest with the contents of this article.

\subsubsection{Ethical approval}

Not applicable.

\subsubsection{Consent to participate}

Not applicable.

\subsubsection{Consent for publication}

Not applicable.

\section{References}

1. Williams JW, Plassman BL, Burke J, Benjamin S (2010) Preventing Alzheimer's disease and cognitive decline. Evid Rep Technol Assess (Full Rep) (193):1-727

2. DeTure MA, Dickson DW (2019) The neuropathological diagnosis of Alzheimer's disease. Mol Neurodegener 14(1):32. doi:10.1186/s13024-019-0333-5

3. Kehoe PG, Wong S, Al Mulhim N, Palmer LE, Miners JS (2016) Angiotensin-converting enzyme 2 is reduced in Alzheimer's disease in association with increasing amyloid-beta and tau pathology. Alzheimers Res Ther 8(1):50. doi:10.1186/s13195-016-0217-7

4. Wyss-Coray T, Mucke L (2002) Inflammation in neurodegenerative disease--a double-edged sword. Neuron 35(3):419-432. doi:10.1016/s0896-6273(02)00794-8 
5. Kempuraj D, Thangavel R, Natteru PA, Selvakumar GP, Saeed D, Zahoor H, Zaheer S, lyer SS, Zaheer A (2016) Neuroinflammation Induces Neurodegeneration. J Neurol Neurosurg Spine 1 (1)

6. Shabab T, Khanabdali R, Moghadamtousi SZ, Kadir HA, Mohan G (2017) Neuroinflammation pathways: a general review. Int J Neurosci 127(7):624-633. doi:10.1080/00207454.2016.1212854

7. Ransohoff RM (2016) How neuroinflammation contributes to neurodegeneration. Science 353(6301):777-783. doi:10.1126/science.aag2590

8. Salkovic-Petrisic M, Osmanovic J, Grunblatt E, Riederer P, Hoyer S (2009) Modeling sporadic Alzheimer's disease: the insulin resistant brain state generates multiple long-term morphobiological abnormalities including hyperphosphorylated tau protein and amyloid-beta. J Alzheimers Dis 18(4):729-750. doi:10.3233/JAD-2009-1184

9. Salkovic-Petrisic M, Hoyer S (2007) Central insulin resistance as a trigger for sporadic Alzheimer-like pathology: an experimental approach. J Neural Transm Suppl (72):217-233. doi:10.1007/978-3-21173574-9_28

10. Grieb P (2016) Intracerebroventricular Streptozotocin Injections as a Model of Alzheimer's Disease: in Search of a Relevant Mechanism. Mol Neurobiol 53(3):1741-1752. doi:10.1007/s12035-015-9132-3

11. Liu Y, Liu F, Grundke-Iqbal I, Iqbal K, Gong CX (2011) Deficient brain insulin signalling pathway in Alzheimer's disease and diabetes. J Pathol 225(1):54-62. doi:10.1002/path.2912

12. Chen Y, Liang Z, Blanchard J, Dai CL, Sun S, Lee MH, Grundke-lqbal I, Iqbal K, Liu F, Gong CX (2013) A non-transgenic mouse model (icv-STZ mouse) of Alzheimer's disease: similarities to and differences from the transgenic model (3xTg-AD mouse). Mol Neurobiol 47(2):711-725. doi:10.1007/s12035012-8375-5

13. Saxena G, Patro IK, Nath C (2011) ICV STZ induced impairment in memory and neuronal mitochondrial function: A protective role of nicotinic receptor. Behav Brain Res 224(1):50-57. doi:10.1016/j.bbr.2011.04.039

14. Tiwari V, Kuhad A, Bishnoi M, Chopra K (2009) Chronic treatment with tocotrienol, an isoform of vitamin E, prevents intracerebroventricular streptozotocin-induced cognitive impairment and oxidative-nitrosative stress in rats. Pharmacol Biochem Behav 93(2):183-189. doi:10.1016/j.pbb.2009.05.009

15. Weller J, Budson A (2018) Current understanding of Alzheimer's disease diagnosis and treatment. F1000Res 7. doi:10.12688/f1000research.14506.1

16. Kamel AS, Abdelkader NF, Abd El-Rahman SS, Emara M, Zaki HF, Khattab MM (2018) Stimulation of ACE2/ANG(1-7)/Mas Axis by Diminazene Ameliorates Alzheimer's Disease in the D-GalactoseOvariectomized Rat Model: Role of PI3K/Akt Pathway. Mol Neurobiol 55(10):8188-8202. doi:10.1007/s12035-018-0966-3

17. Wright JW, Harding JW (2019) Contributions by the Brain Renin-Angiotensin System to Memory, Cognition, and Alzheimer's Disease. J Alzheimers Dis 67(2):469-480. doi:10.3233/JAD-181035

18. Amin FU, Shah SA, Kim MO (2016) Glycine inhibits ethanol-induced oxidative stress, neuroinflammation and apoptotic neurodegeneration in postnatal rat brain. Neurochem Int 96:1-12. 
doi:10.1016/j.neuint.2016.04.001

19. Goel R, Bhat SA, Rajasekar N, Hanif K, Nath C, Shukla R (2015) Hypertension exacerbates predisposition to neurodegeneration and memory impairment in the presence of a neuroinflammatory stimulus: Protection by angiotensin converting enzyme inhibition. Pharmacol Biochem Behav 133:132-145. doi:10.1016/j.pbb.2015.04.002

20. Barnes JM, Barnes NM, Costall B, Coughlan J, Kelly ME, Naylor RJ, Tomkins DM, Williams TJ (1992) Angiotensin-converting enzyme inhibition, angiotensin, and cognition. J Cardiovasc Pharmacol 19 Suppl 6:S63-S71. doi:10.1097/00005344-199219006-00011

21. Bartus RT, Dean RL 3rd, Beer B, Lippa AS (1982) The cholinergic hypothesis of geriatric memory dysfunction. Science 217(4558):408-414. doi:10.1126/science.7046051

22. Hou DR, Wang Y, Zhou L, Chen K, Tian Y, Song Z, Bao J, Yang QD (2008) Altered angiotensinconverting enzyme and its effects on the brain in a rat model of Alzheimer disease. Chin Med $\mathrm{J}$ (Engl) 121(22):2320-2323

23. Tota S, Hanif K, Kamat PK, Najmi AK, Nath C (2012) Role of central angiotensin receptors in scopolamine-induced impairment in memory, cerebral blood flow, and cholinergic function. Psychopharmacology 222(2):185-202. doi:10.1007/s00213-012-2639-7

24. Tota S, Kamat PK, Saxena G, Hanif K, Najmi AK, Nath C (2012) Central angiotensin converting enzyme facilitates memory impairment in intracerebroventricular streptozotocin treated rats. Behav Brain Res 226(1):317-330. doi:10.1016/j.bbr.2011.07.047

25. Tota S, Goel R, Pachauri SD, Rajasekar N, Najmi AK, Hanif K, Nath C (2013) Effect of angiotensin II on spatial memory, cerebral blood flow, cholinergic neurotransmission, and brain derived neurotrophic factor in rats. Psychopharmacology 226(2):357-369. doi:10.1007/s00213-012-2913-8

26. Carvalho C, Moreira PI (2018) Oxidative Stress: A Major Player in Cerebrovascular Alterations Associated to Neurodegenerative Events. Front Physiol 9:806. doi:10.3389/fphys.2018.00806

27. Doobay MF, Talman LS, Obr TD, Tian X, Davisson RL, Lazartigues E (2007) Differential expression of neuronal ACE2 in transgenic mice with overexpression of the brain renin-angiotensin system. Am $\mathrm{J}$ Physiol Regul Integr Comp Physiol 292(1):R373-R381. doi:10.1152/ajpregu.00292.2006

28. Gallagher PE, Chappell MC, Ferrario CM, Tallant EA (2006) Distinct roles for ANG II and ANG-(1-7) in the regulation of angiotensin-converting enzyme 2 in rat astrocytes. Am J Physiol Cell Physiol 290(2):C420-C426. doi:10.1152/ajpcell.00409.2004

29. Hamming I, Timens W, Bulthuis ML, Lely AT, Navis G, van Goor H (2004) Tissue distribution of ACE2 protein, the functional receptor for SARS coronavirus. A first step in understanding SARS pathogenesis. J Pathol 203(2):631-637. doi:10.1002/path.1570

30. Gironacci MM, Vicario A, Cerezo G, Silva MG (2018) The depressor axis of the renin-angiotensin system and brain disorders: a translational approach. Clin Sci (Lond) 132(10):1021-1038. doi:10.1042/CS20180189

31. Liu S, Liu J, Miura Y, Tanabe C, Maeda T, Terayama Y, Turner AJ, Zou K, Komano H (2014) Conversion of Abeta43 to Abeta40 by the successive action of angiotensin-converting enzyme 2 and 
angiotensin-converting enzyme. J Neurosci Res 92(9):1178-1186. doi:10.1002/jnr.23404

32. Xie W, Zhu D, Ji L, Tian M, Xu C, Shi J (2014) Angiotensin-(1-7) improves cognitive function in rats with chronic cerebral hypoperfusion. Brain Res 1573:44-53. doi:10.1016/j.brainres.2014.05.019

33. Jiang T, Gao L, Guo J, Lu J, Wang Y, Zhang Y (2012) Suppressing inflammation by inhibiting the NFkappaB pathway contributes to the neuroprotective effect of angiotensin-(1-7) in rats with permanent cerebral ischaemia. Br J Pharmacol 167(7):1520-1532. doi:10.1111/j.1476-5381.2012.02105.x

34. Goldstein J, Loidl CF, Creydt VP, Boccoli J, Ibarra C (2007) Intracerebroventricular administration of Shiga toxin type 2 induces striatal neuronal death and glial alterations: an ultrastructural study. Brain Res 1161:106-115. doi:10.1016/j.brainres.2007.05.067

35. Pena Silva RA, Chu Y, Miller JD, Mitchell IJ, Penninger JM, Faraci FM, Heistad DD (2012) Impact of ACE2 deficiency and oxidative stress on cerebrovascular function with aging. Stroke 43(12):33583363. doi:10.1161/STROKEAHA. 112.667063

36. Kuriakose S, Uzonna JE (2014) Diminazene aceturate (Berenil), a new use for an old compound? Int Immunopharmacol 21(2):342-345. doi:10.1016/j.intimp.2014.05.027

37. Shenoy V, Gjymishka A, Jarajapu YP, Qi Y, Afzal A, Rigatto K, Ferreira AJ, Fraga-Silva RA, Kearns P, Douglas JY, Agarwal D, Mubarak KK, Bradford C, Kennedy WR, Jun JY, Rathinasabapathy A, Bruce E, Gupta D, Cardounel AJ, Mocco J, Patel JM, Francis J, Grant MB, Katovich MJ, Raizada MK (2013) Diminazene attenuates pulmonary hypertension and improves angiogenic progenitor cell functions in experimental models. Am J Respir Crit Care Med 187(6):648-657. doi:10.1164/rccm.201205$08800 \mathrm{C}$

38. Nami B, Ghanaeian A, Ghanaeian K, Houri R, Nami N, Ghasemi-Dizgah A, Caluseriu O (2021) The interaction of the severe acute respiratory syndrome coronavirus 2 spike protein with drug-inhibited angiotensin converting enzyme 2 studied by molecular dynamics simulation. J Hypertens 39(8):1705-1716. doi:10.1097/HJH.0000000000002829

39. Gowrisankar YV, Clark MA (2016) Angiotensin II regulation of angiotensin-converting enzymes in spontaneously hypertensive rat primary astrocyte cultures. J Neurochem 138(1):74-85. doi:10.1111/jnc.13641

40. Pabbidi RM, Cao DS, Parihar A, Pauza ME, Premkumar LS (2008) Direct role of streptozotocin in inducing thermal hyperalgesia by enhanced expression of transient receptor potential vanilloid 1 in sensory neurons. Mol Pharmacol 73(3):995-1004. doi:10.1124/mol.107.041707

41. Rajasekar N, Dwivedi S, Nath C, Hanif K, Shukla R (2014) Protection of streptozotocin induced insulin receptor dysfunction, neuroinflammation and amyloidogenesis in astrocytes by insulin.

Neuropharmacology 86:337-352. doi:10.1016/j.neuropharm.2014.08.013

42. Bhat SA, Goel R, Shukla R, Hanif K (2016) Angiotensin Receptor Blockade Modulates NFkappaB and STAT3 Signaling and Inhibits Glial Activation and Neuroinflammation Better than AngiotensinConverting Enzyme Inhibition. Mol Neurobiol 53(10):6950-6967. doi:10.1007/s12035-015-9584-5

43. Wu Z, Zhu A, Takayama F, Okada R, Liu Y, Harada Y, Wu S, Nakanishi H (2013) Brazilian green propolis suppresses the hypoxia-induced neuroinflammatory responses by inhibiting NF-kappaB 
activation in microglia. Oxid Med Cell Longev 2013:906726. doi:10.1155/2013/906726

44. Ellman GL, Courtney KD, Andres V Jr, Feather-Stone RM (1961) A new and rapid colorimetric determination of acetylcholinesterase activity. Biochem Pharmacol 7:88-95. doi:10.1016/00062952(61)90145-9

45. Sivandzade F, Bhalerao A, Cucullo L (2019) Analysis of the Mitochondrial Membrane Potential Using the Cationic JC-1 Dye as a Sensitive Fluorescent Probe. Bio Protoc 9 (1). doi:10.21769/BioProtoc.3128

46. Elefantova K, Lakatos B, Kubickova J, Sulova Z, Breier A (2018) Detection of the Mitochondrial Membrane Potential by the Cationic Dye JC-1 in L1210 Cells with Massive Overexpression of the Plasma Membrane ABCB1 Drug Transporter. Int J Mol Sci 19 (7). doi:10.3390/ijms19071985

47. Yan Y, Gong K, Ma T, Zhang L, Zhao N, Zhang X, Tang P, Gong Y (2012) Protective effect of edaravone against Alzheimer's disease-relevant insults in neuroblastoma N2a cells. Neurosci Lett 531(2):160-165. doi:10.1016/j.neulet.2012.10.043

48. Heni M, Hennige AM, Peter A, Siegel-Axel D, Ordelheide AM, Krebs N, Machicao F, Fritsche A, Haring HU, Staiger H (2011) Insulin promotes glycogen storage and cell proliferation in primary human astrocytes. PLoS One 6(6):e21594. doi:10.1371/journal.pone.0021594

49. Singh S, Mishra A, Bharti S, Tiwari V, Singh J, Parul, Shukla S (2018) Glycogen Synthase Kinase3beta Regulates Equilibrium Between Neurogenesis and Gliogenesis in Rat Model of Parkinson's Disease: a Crosstalk with Wnt and Notch Signaling. Mol Neurobiol 55(8):6500-6517. doi:10.1007/s12035-017-0860-4

50. Niranjan R, Nath C, Shukla R (2010) The mechanism of action of MPTP-induced neuroinflammation and its modulation by melatonin in rat astrocytoma cells, C6. Free Radic Res 44(11):1304-1316. doi:10.3109/10715762.2010.501080

51. Vina J, Lloret A (2010) Why women have more Alzheimer's disease than men: gender and mitochondrial toxicity of amyloid-beta peptide. J Alzheimers Dis 20(Suppl 2):S527-S533. doi:10.3233/JAD-2010-100501

52. Dufouil C, Seshadri S, Chene G (2014) Cardiovascular risk profile in women and dementia. J Alzheimers Dis 42(Suppl 4):S353-S363. doi:10.3233/JAD-141629

53. Mehla J, Pahuja M, Gupta YK (2013) Streptozotocin-induced sporadic Alzheimer's disease: selection of appropriate dose. J Alzheimers Dis 33(1):17-21. doi:10.3233/JAD-2012-120958

54. Mishra SK, Singh S, Shukla S, Shukla R (2018) Intracerebroventricular streptozotocin impairs adult neurogenesis and cognitive functions via regulating neuroinflammation and insulin signaling in adult rats. Neurochem Int 113:56-68. doi:10.1016/j.neuint.2017.11.012

55. Tiwari V, Mishra A, Singh S, Mishra SK, Sahu KK, Parul, Kulkarni MJ, Shukla R, Shukla S (2021) Protriptyline improves spatial memory and reduces oxidative damage by regulating NFkappaBBDNF/CREB signaling axis in streptozotocin-induced rat model of Alzheimer's disease. Brain Res 1754:147261. doi:10.1016/j.brainres.2020.147261 
56. Bruce EB, Sakarya Y, Kirichenko N, Toklu HZ, Sumners C, Morgan D, Tumer N, Scarpace PJ, Carter CS (2018) ACE2 activator diminazene aceturate reduces adiposity but preserves lean mass in young and old rats. Exp Gerontol 111:133-140. doi:10.1016/j.exger.2018.07.008

57. Goru SK, Kadakol A, Malek V, Pandey A, Sharma N, Gaikwad AB (2017) Diminazene aceturate prevents nephropathy by increasing glomerular ACE2 and AT2 receptor expression in a rat model of type1 diabetes. Br J Pharmacol 174(18):3118-3130. doi:10.1111/bph.13946

58. Evans CE, Miners JS, Piva G, Willis CL, Heard DM, Kidd EJ, Good MA, Kehoe PG (2020) ACE2 activation protects against cognitive decline and reduces amyloid pathology in the Tg2576 mouse model of Alzheimer's disease. Acta Neuropathol 139(3):485-502. doi:10.1007/s00401-019-02098-6

59. Singh S, Mishra A, Srivastava N, Shukla R, Shukla S (2018) Acetyl-L-Carnitine via Upegulating Dopamine D1 Receptor and Attenuating Microglial Activation Prevents Neuronal Loss and Improves Memory Functions in Parkinsonian Rats. Mol Neurobiol 55(1):583-602. doi:10.1007/s12035-0160293-5 1007/s12035-016-0293-5 [pii]

60. Mishra A, Singh S, Tiwari V, Chaturvedi S, Wahajuddin M, Shukla S (2019) Dopamine receptor activation mitigates mitochondrial dysfunction and oxidative stress to enhance dopaminergic neurogenesis in 6-OHDA lesioned rats: A role of Wnt signalling. Neurochem Int 129:104463. doi:10.1016/j.neuint.2019.104463

61. Bennion DM, Haltigan EA, Irwin AJ, Donnangelo LL, Regenhardt RW, Pioquinto DJ, Purich DL, Sumners C (2015) Activation of the Neuroprotective Angiotensin-Converting Enzyme 2 in Rat Ischemic Stroke. Hypertension 66(1):141-148. doi:10.1161/HYPERTENSIONAHA.115.05185

62. Gironacci MM, Cerniello FM, Longo Carbajosa NA, Goldstein J, Cerrato BD (2014) Protective axis of the renin-angiotensin system in the brain. Clin Sci (Lond) 127(5):295-306. doi:10.1042/CS20130450

63. Gouveia TL, Frangiotti MI, de Brito JM, de Castro Neto EF, Sakata MM, Febba AC, Casarini DE, Amado D, Cavalheiro EA, Almeida SS, Manchini MT, Araujo RC, Silva JA Jr, Naffah-Mazzacoratti Mda G (2012) The levels of renin-angiotensin related components are modified in the hippocampus of rats submitted to pilocarpine model of epilepsy. Neurochem Int 61(1):54-62.

doi:10.1016/j.neuint.2012.04.012

64. Nahdi A, John A, Raza H (2017) Elucidation of Molecular Mechanisms of Streptozotocin-Induced Oxidative Stress, Apoptosis, and Mitochondrial Dysfunction in Rin-5F Pancreatic beta-Cells. Oxid Med Cell Longev 2017:7054272. doi:10.1155/2017/7054272

65. Studer R, Baysang G, Brack C (2001) N-Acetyl-L-Cystein downregulates beta-amyloid precursor protein gene transcription in human neuroblastoma cells. Biogerontology 2(1):55-60. doi:10.1023/a:1010065103073

66. Cabezas-Opazo FA, Vergara-Pulgar K, Perez MJ, Jara C, Osorio-Fuentealba C, Quintanilla RA (2015) Mitochondrial Dysfunction Contributes to the Pathogenesis of Alzheimer's Disease. Oxid Med Cell Longev 2015:509654. doi:10.1155/2015/509654

67. Deshpande A, Mina E, Glabe C, Busciglio J (2006) Different conformations of amyloid beta induce neurotoxicity by distinct mechanisms in human cortical neurons. J Neurosci 26(22):6011-6018. 
doi:10.1523/JNEUROSCI.1189-06.2006

68. Xie H, Guan J, Borrelli LA, Xu J, Serrano-Pozo A, Bacskai BJ (2013) Mitochondrial alterations near amyloid plaques in an Alzheimer's disease mouse model. J Neurosci 33(43):17042-17051. doi:10.1523/JNEUROSCI.1836-13.2013

69. Wang Y, Shi Y, Wei H (2017) Calcium Dysregulation in Alzheimer's Disease: A Target for New Drug Development. J Alzheimers Dis Parkinsonism 7 (5). doi:10.4172/2161-0460.1000374

70. Szabo G, Csak T (2012) Inflammasomes in liver diseases. J Hepatol 57(3):642-654. doi:10.1016/j.jhep.2012.03.035

71. Watanabe A, Sohail MA, Gomes DA, Hashmi A, Nagata J, Sutterwala FS, Mahmood S, Jhandier MN, Shi Y, Flavell RA, Mehal WZ (2009) Inflammasome-mediated regulation of hepatic stellate cells. Am J Physiol Gastrointest Liver Physiol 296(6):G1248-G1257. doi:10.1152/ajpgi.90223.2008

72. Halle A, Hornung V, Petzold GC, Stewart CR, Monks BG, Reinheckel T, Fitzgerald KA, Latz E, Moore KJ, Golenbock DT (2008) The NALP3 inflammasome is involved in the innate immune response to amyloid-beta. Nat Immunol 9(8):857-865. doi:10.1038/ni.1636

73. Sun NN, Yu CH, Pan MX, Zhang Y, Zheng BJ, Yang QJ, Zheng ZM, Meng Y (2017) Mir-21 Mediates the Inhibitory Effect of Ang (1-7) on Angll-induced NLRP3 Inflammasome Activation by Targeting Spry1 in lung fibroblasts. Sci Rep 7(1):14369. doi:10.1038/s41598-017-13305-3

74. Olabarria M, Noristani HN, Verkhratsky A, Rodriguez JJ (2010) Concomitant astroglial atrophy and astrogliosis in a triple transgenic animal model of Alzheimer's disease. Glia 58(7):831-838. doi:10.1002/glia.20967

75. Jucker M, Walker LC (2015) Neurodegeneration: Amyloid-beta pathology induced in humans. Nature 525(7568):193-194. doi:10.1038/525193a

76. Leyns CEG, Holtzman DM (2017) Glial contributions to neurodegeneration in tauopathies. Mol Neurodegener 12(1):50. doi:10.1186/s13024-017-0192-x

77. Graham NS, Sharp DJ (2019) Understanding neurodegeneration after traumatic brain injury: from mechanisms to clinical trials in dementia. J Neurol Neurosurg Psychiatry 90(11):1221-1233. doi:10.1136/jnnp-2017-317557

78. Duan R, Xue X, Zhang QQ, Wang SY, Gong PY, Jiang EY, Zhang T YD (2020) ACE2 activator diminazene aceturate ameliorates Alzheimer's disease-like neuropathology and rescues cognitive impairment in SAMP8 mice. Aging 12(14):14819-14829. doi:10.18632/aging.103544

79. Rigatto K, Casali KR, Shenoy V, Katovich MJ, Raizada MK (2013) Diminazene aceturate improves autonomic modulation in pulmonary hypertension. Eur J Pharmacol 713(1-3):89-93. doi:10.1016/j.ejphar.2013.04.017

80. Soreq H, Seidman S (2001) Acetylcholinesterase--new roles for an old actor. Nat Rev Neurosci 2(4):294-302. doi:10.1038/35067589

81. Rossi A, Burkhart C, Dell-Kuster S, Pollock BG, Strebel SP, Monsch AU, Kern C, Steiner LA (2014) Serum anticholinergic activity and postoperative cognitive dysfunction in elderly patients. Anesth Analg 119(4):947-955. doi:10.1213/ANE.0000000000000390 
82. Raffai G, Lombard JH (2016) Angiotensin-(1-7) Selectively Induces Relaxation and Modulates Endothelium-Dependent Dilation in Mesenteric Arteries of Salt-Fed Rats. J Vasc Res 53(1-2):105118. doi:10.1159/000448714

\section{Figures}
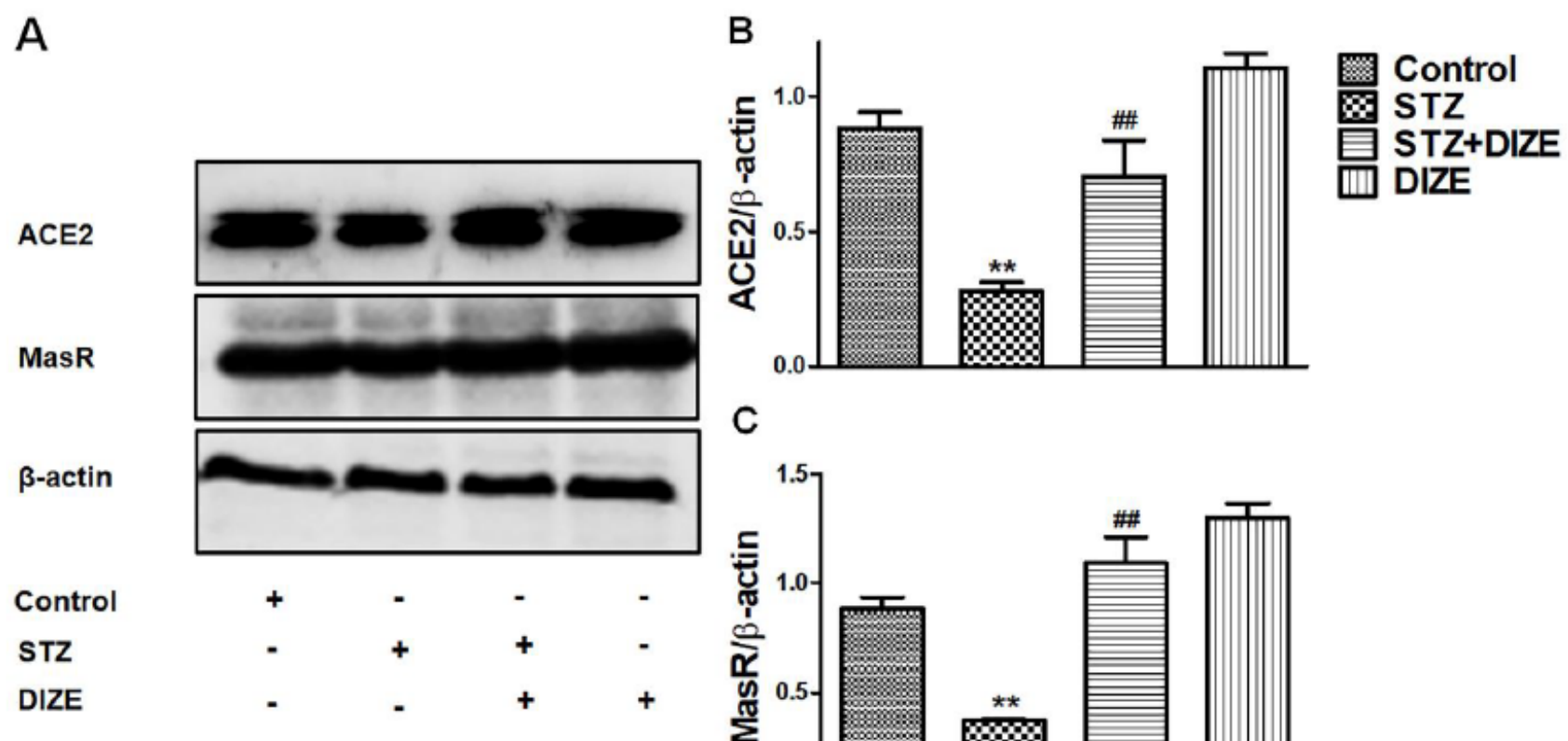

D

E

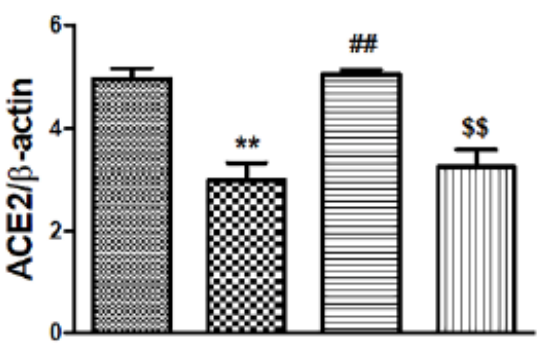

Control

Q STZ

ACE2

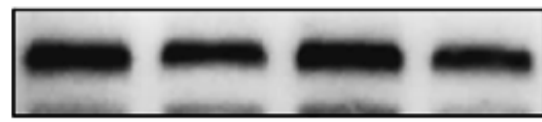

MasR

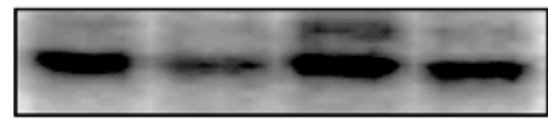

$\beta$-actin
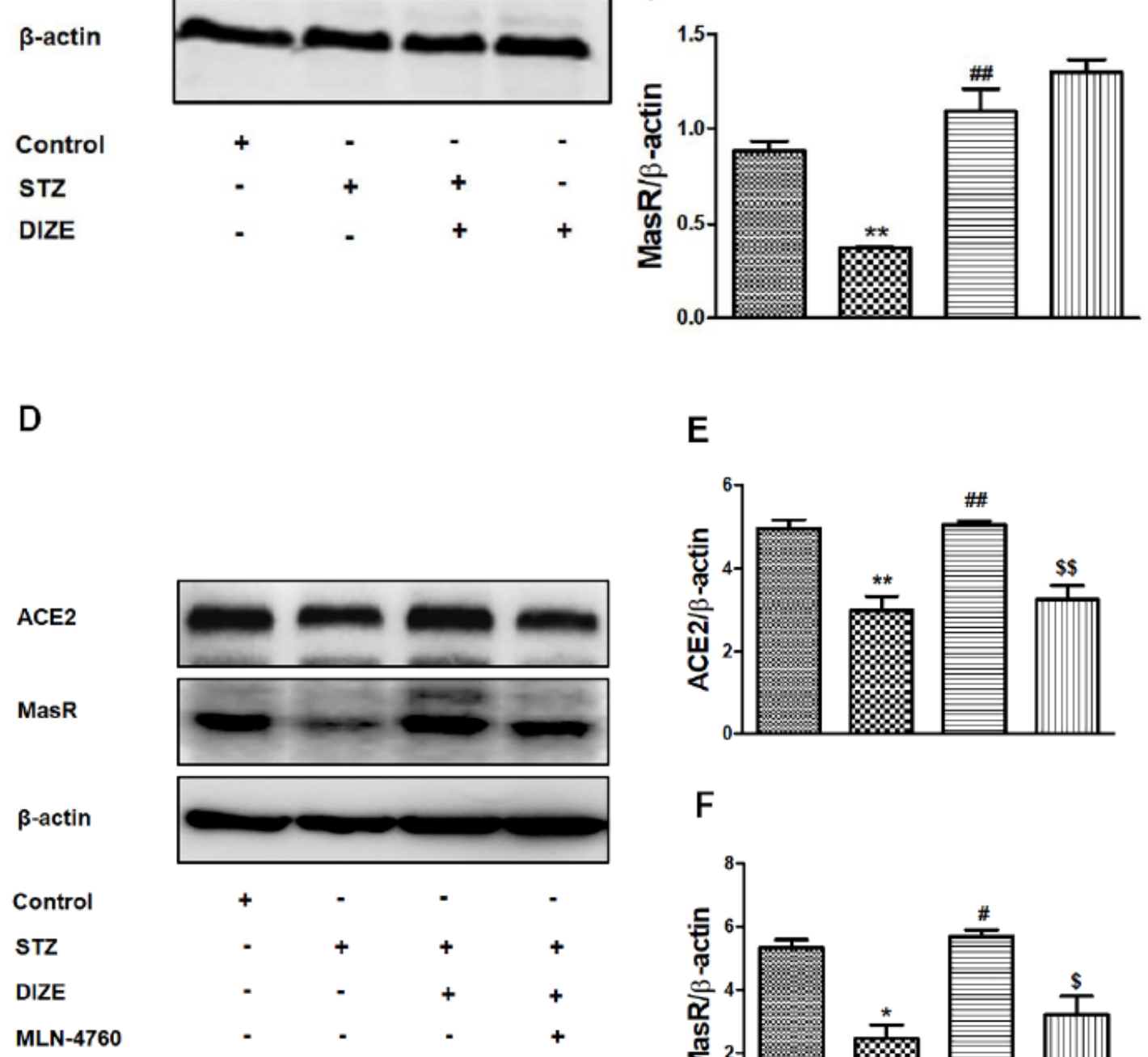

$\mathrm{F}$

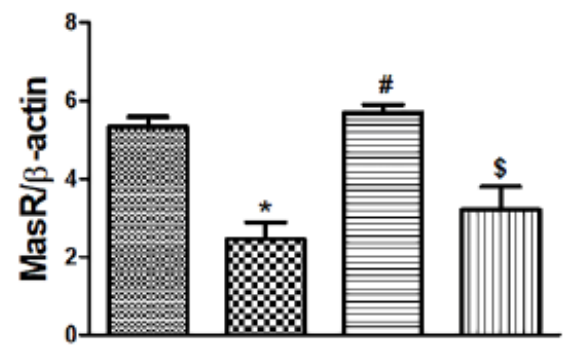

Figure 1 
Activation of ACE2/Ang-(1-7)/MasR axis upon DIZE treatment in N2A cells. A. Representative immunoblots show expression of ACE2 and MasR in STZ administered N2A cells. The bar graphs show quantification of relative protein density of B. ACE2 and C. MasR after DIZE treatment in STZ exposed N2A cells. D. The immunoblots shows antagonistic effect of MLN-4760, an ACE2 selective inhibitor on activation of ACE2/Ang-(1-7)/MasR after treatment with DIZE in N2A cells exposed to STZ. The bar graph represents quantification of protein densities of E. ACE2, F. MasR, after normalization with $\beta$-actin. Data are expressed as mean \pm SEM of $n=3-4$. Data were analyzed by one-way ANOVA, followed by bonferroni post hoc test $\left({ }^{\star} P<0.05,{ }^{\star} * P<0.01,{ }^{\star * *} P<0.001 ; \# P<0.05, \# \# P<0.01, \# \# \#<0.001 ; \$ P<0.05\right.$,

$$
P<0.01,
$$

$\$ \mathrm{P}<0.001) .{ }^{*}$ Control vs STZ; \#STZ vs STZ+ DIZE, \$STZ vs STZ+ DIZE+MLN-4760.

A

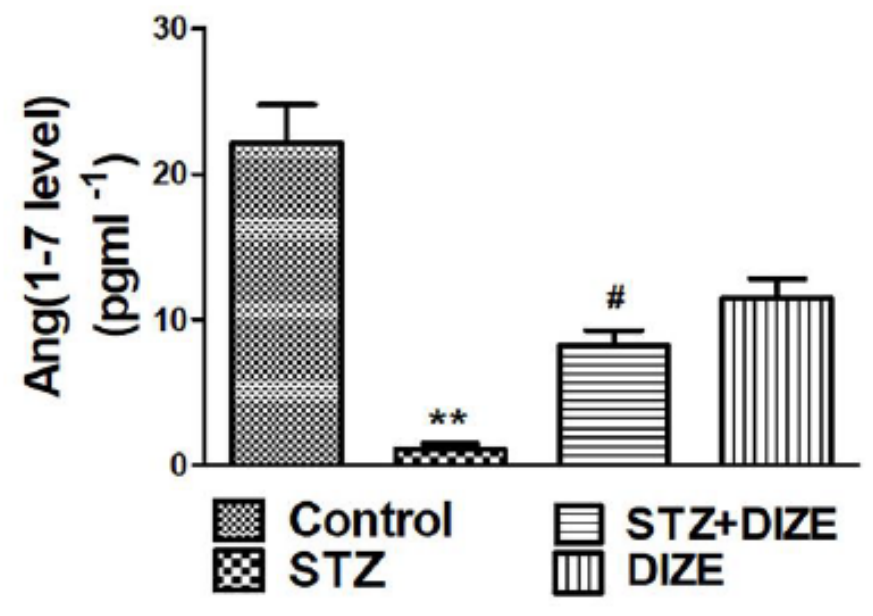

B

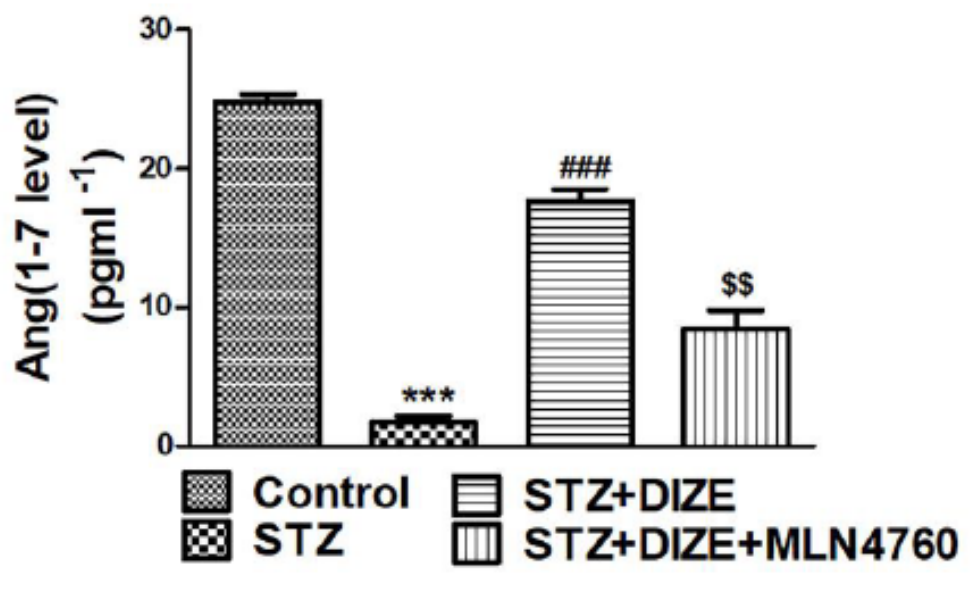

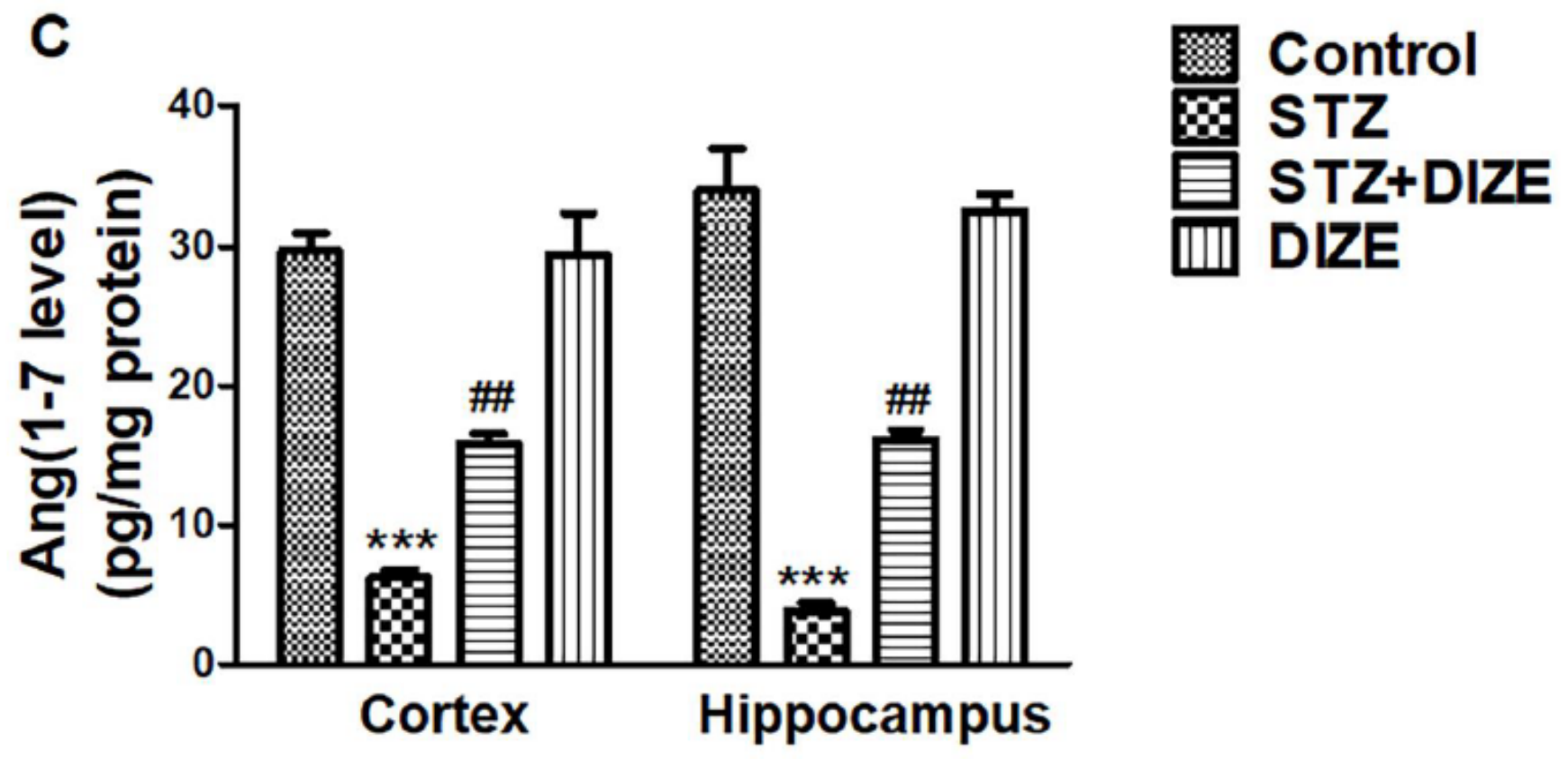


Figure 2

Evaluation of role of Ang-(1-7) in ACE2/Ang-(1-7)/MasR axis activation mediated neuroprotection. A. The bar graphs show quantification of relative level of Ang-(1-7) after treatment with DIZE in N2A cells exposed to STZ. B. Bar graph shows pharmacological antagonism of DIZE mediated Ang (1-7) activation in N2A cells following treatment with MLN-4760. C. representative bar graph shows Ang (1-7) level after DIZE treatment (10 mg/kg i.p.) after STZ lesioning. Data are expressed as mean \pm SEM of $n=3-4$. Data were analyzed by one-way ANOVA/two-way ANOVA, followed by bonferroni post hoc test $\left({ }^{*} \mathrm{P}<0.05\right.$, ${ }^{*} \mathrm{P}<$ $0.01, * \star \star P<0.001 ; \# P<0.05, \# \# P<0.01, \# \# \#<0.001 ; \$ P<0.05$,

$$
P<0.01,
$$

$\$ \mathrm{P}<0.001) .{ }^{*}$ Control vs STZ; \#STZ vs STZ+ DIZE, \$STZ vs STZ+ DIZE+MLN-4760.

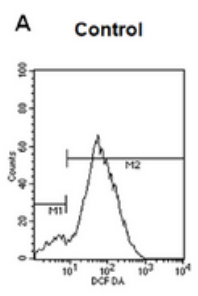

B

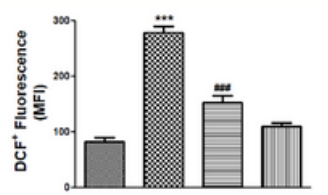

D
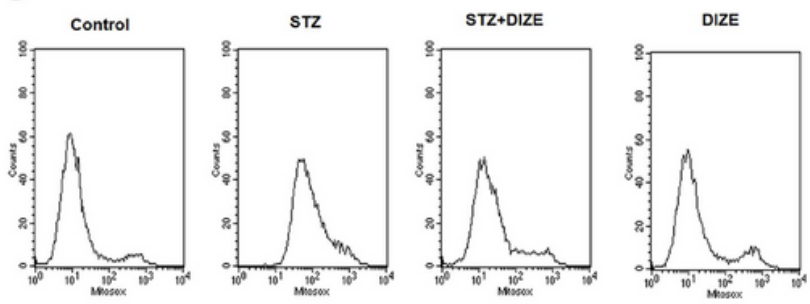

E

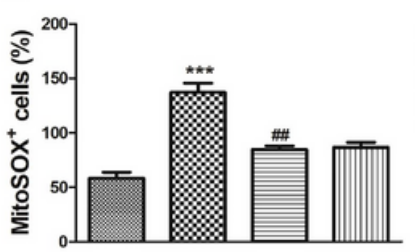

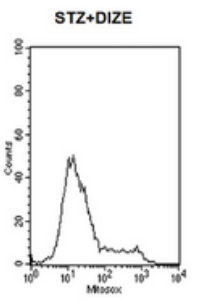

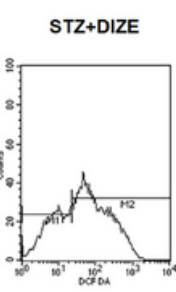

C

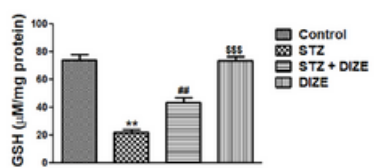

Control

STZ

DIZE

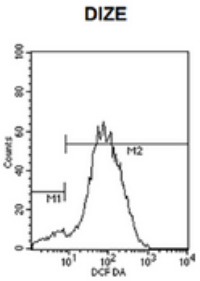

Control
STz
STz + D D
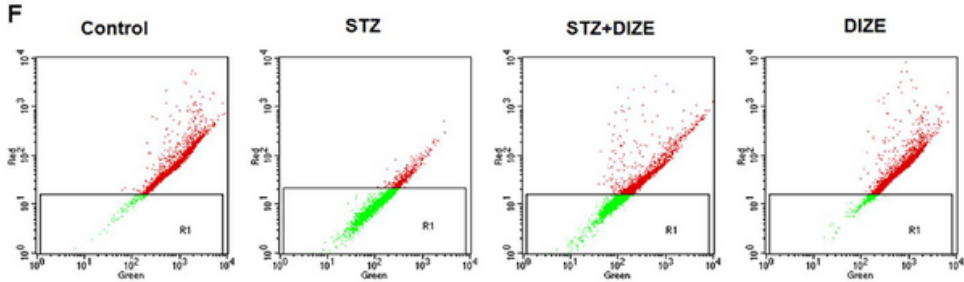

G
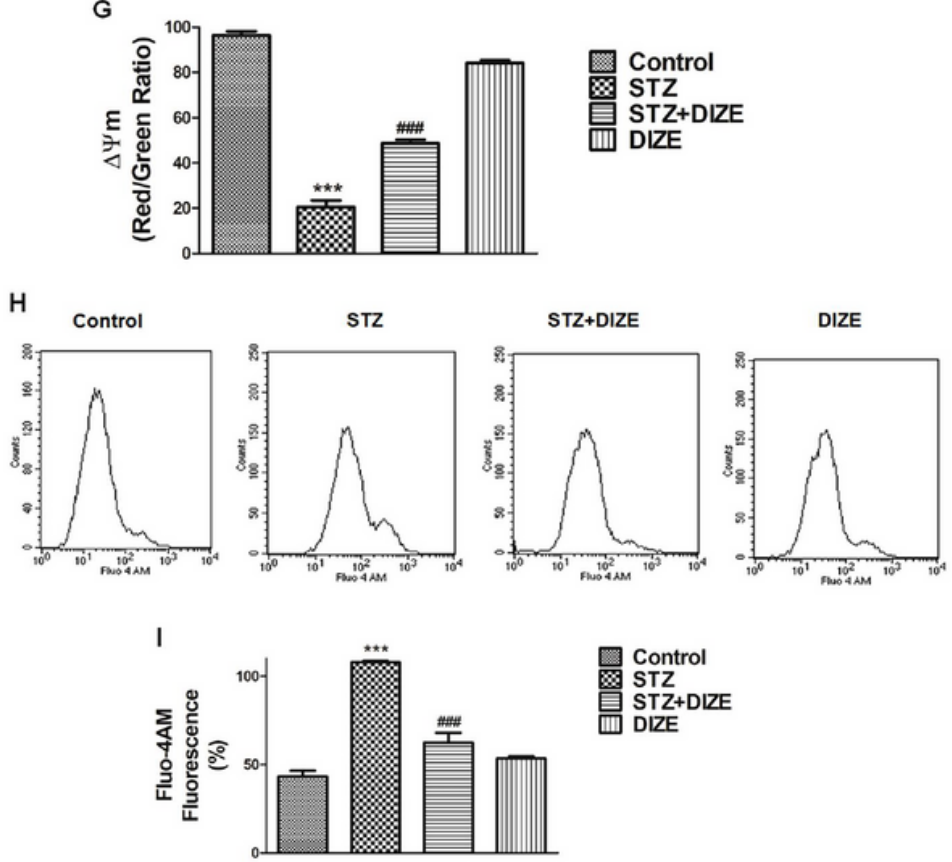

\section{Figure 3}

Activation of ACE2/Ang-(1-7)/MasR axis attenuated oxidative stress burden and improved mitochondrial abnormality in STZ exposed N2A cells A. Flowcytometric image of ROS detection following 2',7'dichlorodihydrofluorescein diacetate addition. B. representative bar graph expressed as mean \pm SEM in triplicate. C. reduced glutathione level after DIZE treatment in STZ exposed N2A cells. D. representative dot plot show attenuation of mtROS generated by STZ exposure in N2A cells, as quantified using flow 
cytometry. E. Histogram show fluorescence intensity of N2A cells. Data are presented as mean of three independent experiments. F. Mitochondrial membrane potential (MMP). Graphical representation of MMP G. quantitative analysis of red/green cells ratio assessed using JC-1dye through flow cytometry after DIZE treatment in STZ exposed N2A cells. H. The detection of Fluo-4AM fluorescence (Ca2+ changes) in N2Acells after exposure to $2.5 \mathrm{mM} \mathrm{STZ} \mathrm{for} 24 \mathrm{~h}$. Representative FACS dot plot with Fluo-4AM

fluorescence. I. Quantitative evaluation of specific fluorescence probe. Data are expressed as mean \pm SEM of $n=3-4$. Data were analyzed by one-way ANOVA, followed by bonferroni post hoc test $\left({ }^{*}<<0.05\right.$, **P $<0.01$, ***P < 0.001; \#P < 0.05, \#\#P < 0.01, \#\#\#P < 0.001). *Control vs STZ; \#STZ vs STZ+ DIZE.
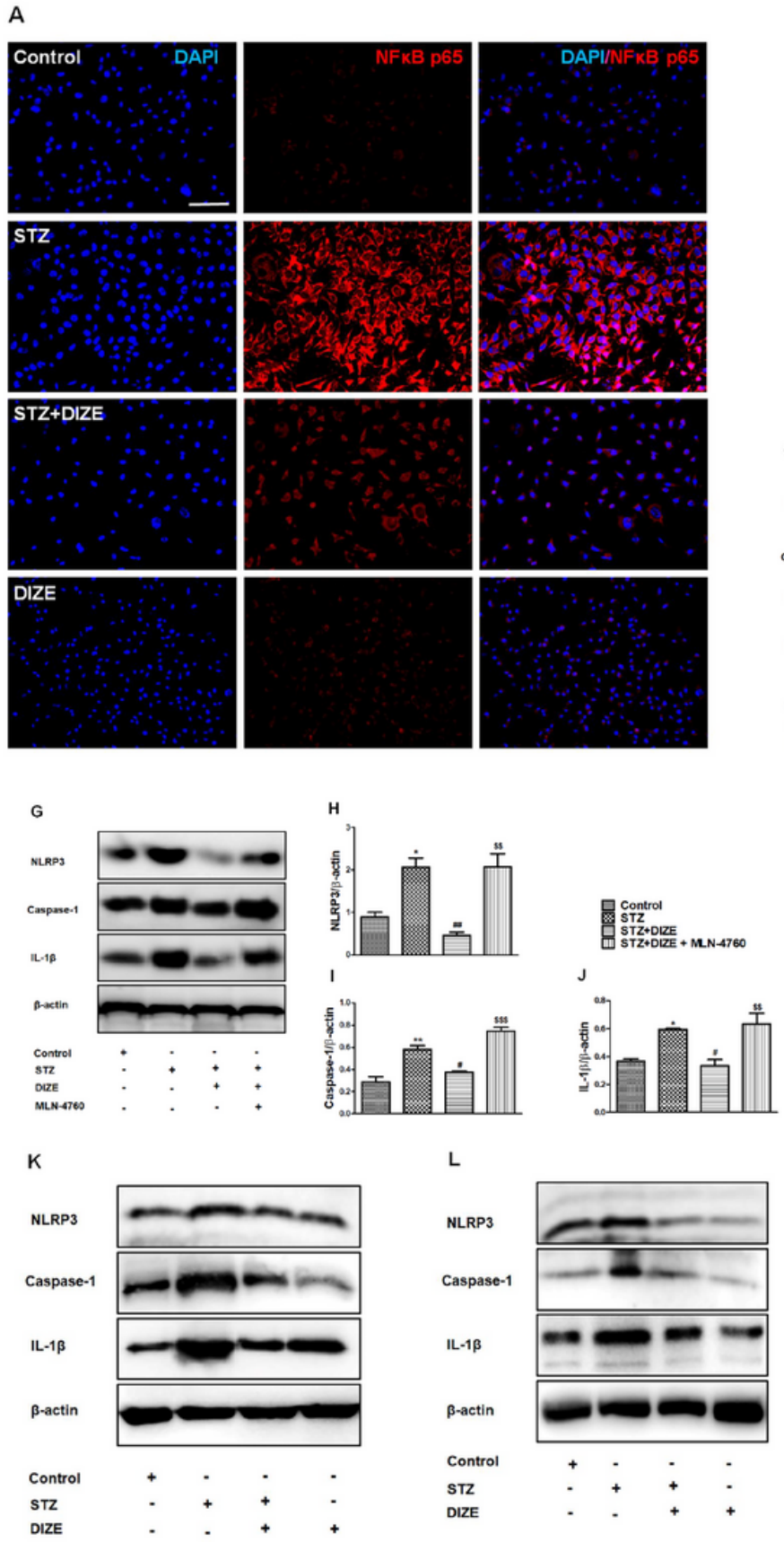

B
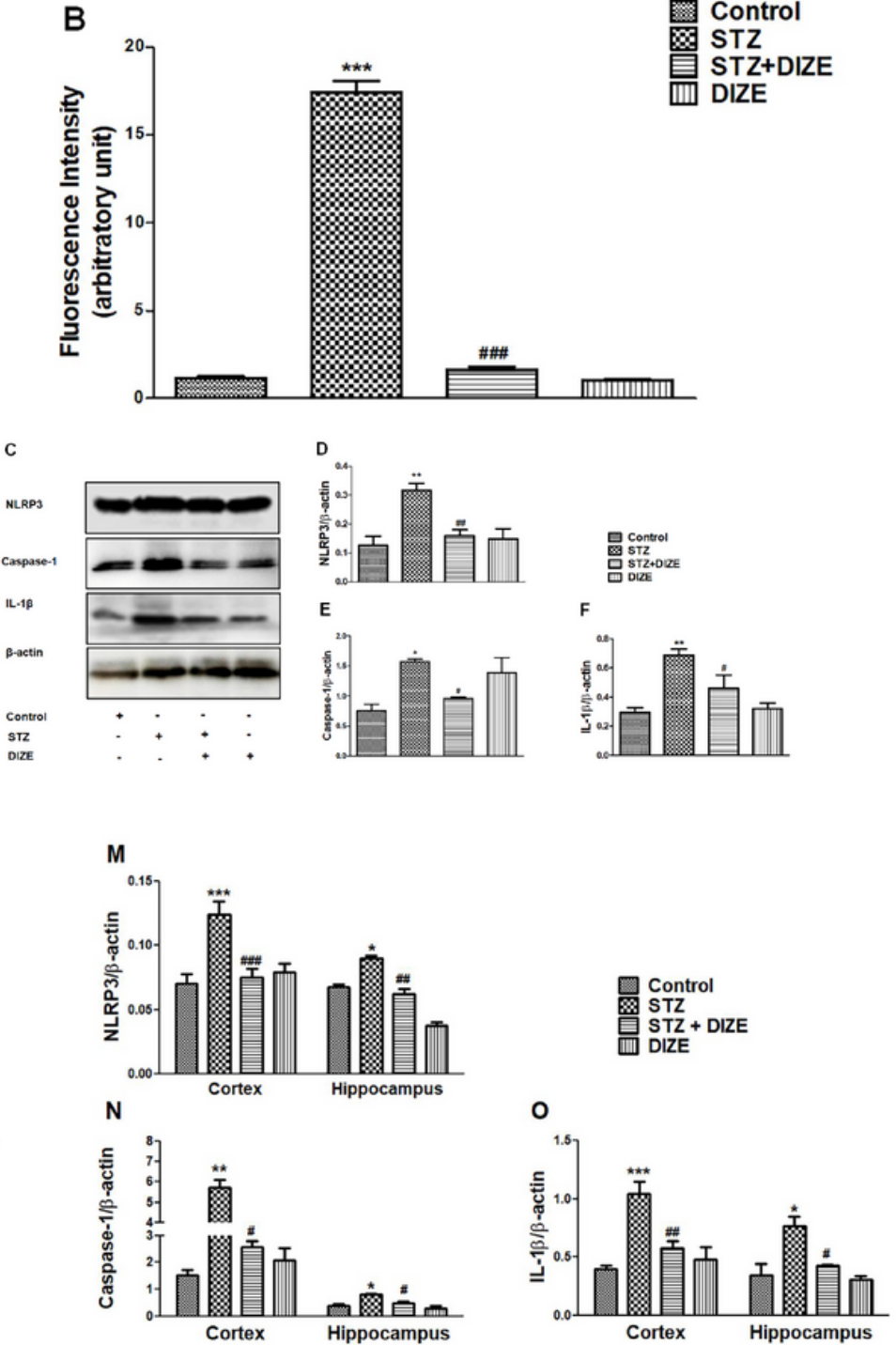

\section{Figure 4}


ACE2/Ang-(1-7)/MasR axis activation downregulate NF-KB induced NLRP3 inflammasome activation in STZ exposed N2A cells . A. Representative photomicrographs show immunostaining of NF-KB (red)/DAPI cells (Blue) after treatment with DIZE in STZ exposed N2Acells. B. The bar graph show quantitative analysis of fluorescence intensity of NF-kB protein. Scale bar, $50 \mu \mathrm{m}$. C. The immunoblots shows protein expression of NLRP3 inflammasome downstream to inflammatory signal NF-KB after treatment with DIZE in N2A cells exposed to STZ. The bar graph represents quantification of protein densities of $D$. NLRP3, E. Capase-1, F. IL-1 $\beta$ after normalization with $\beta$-actin. Pharmacological inhibition of ACE2/Ang-(17)/MasR axis by MLN-4760 enhances NLRP3 inflammasome activation. G. The immunoblots show protein expression of NLRP3 inflammasome after treatment with MLN-4760 along with DIZE in N2A cells exposed to STZ. The bar graph represents quantification of protein densities of H. NLRP3, I. Capase-1, J. IL-1 $\beta$ after normalization with $\beta$-actin. Representative immunoblots shows expression of NLRP3 inflammasome in K. Cortex and L. Hippocampal brain regions. The bar graph represents quantification of protein densities of M. NLRP3, N. Capase-1, O. IL-1 $\beta$ after normalization with $\beta$-actin in both brain regions. Data are expressed as mean \pm SEM of $n=3-4$. Data were analyzed by one-way/two-way ANOVA, followed by Bonferroni post hoc test $\left({ }^{*} P<0.05\right.$, $* * P<0.01$, ${ }^{\star * \star} P<0.001$; $\left.\# P<0.05, \# \# P<0.01, \# \# \# P<0.001\right)$. *Control vs STZ; \#STZ vs STZ+ DIZE; \$STZ vs STZ+ DIZE+MLN-4760.

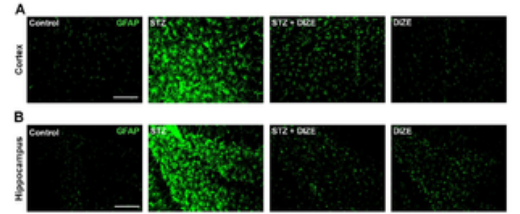

D
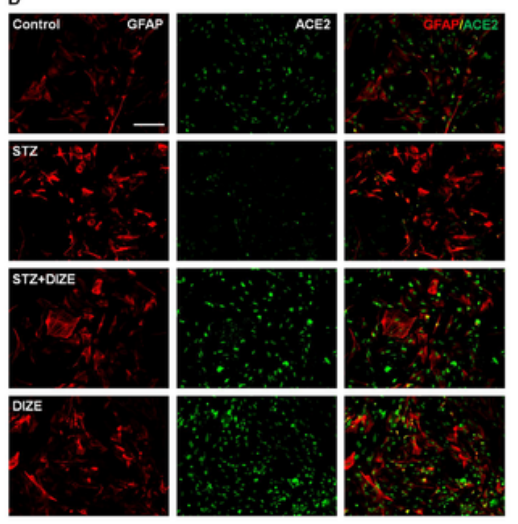
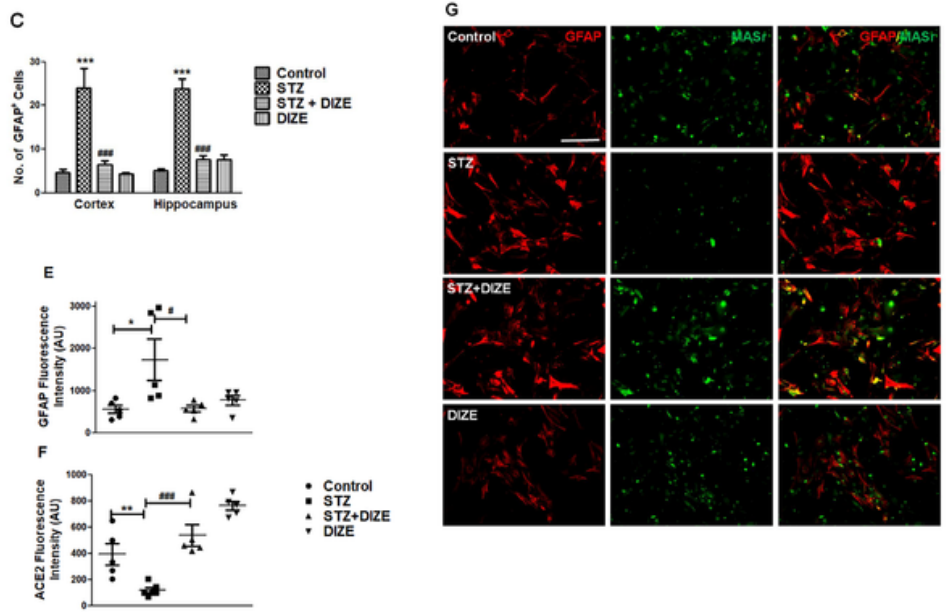
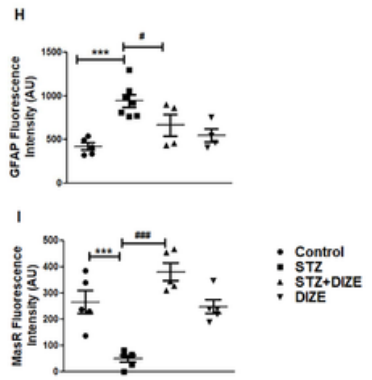

\section{Figure 5}

DIZE mediated activation of ACE2/Ang-(1-7)/MasR ameliorates STZ-induced astroglial activation. Representative photomicrographs show immunostaining of GFAP+ cells (green) in A. cortex B. hippocampus region. Scale bar, $50 \mu \mathrm{m}$. The bar graph shows quantitative analysis of GFAP+ cells in C. cortex and hippocampus region. D. represent immunofluorescence staining of GFAP (red) and ACE2 (green) in primary astrocyte culture. The dot plot shows quantification of immunofluorescence of E. GFAP F. ACE2. G. represent immunofluorescence staining of GFAP (red) and MasR (green) in primary astrocyte culture. The dot plot shows quantification of immunofluorescence of H. GFAP I. MasR. Data are expressed as mean \pm SEM of $n=3-4$. Data were analyzed by one-way/two-way ANOVA, followed by 


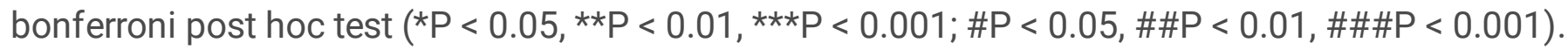
*Control vs STZ; \#STZ vs STZ+ DIZE.
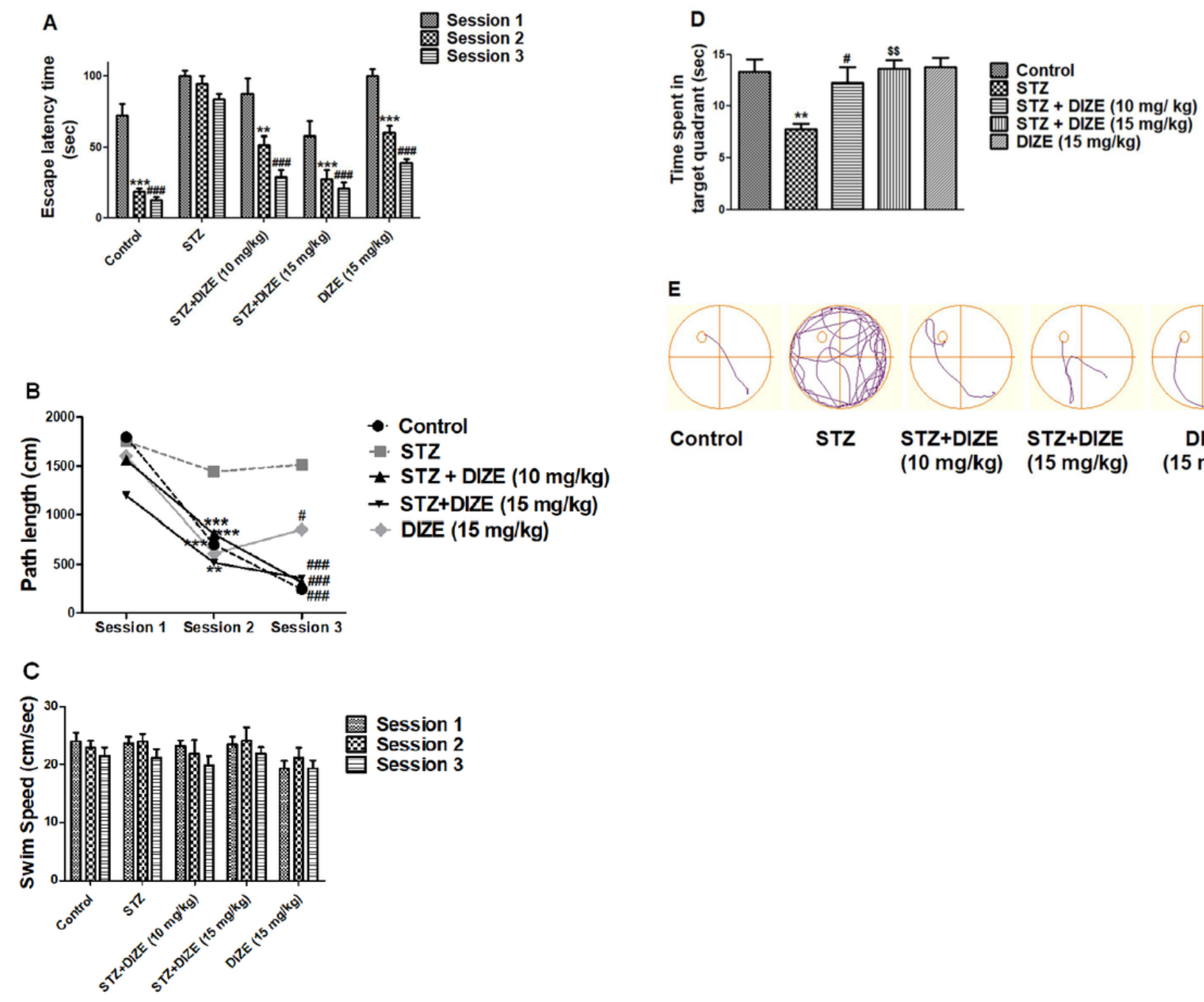

E

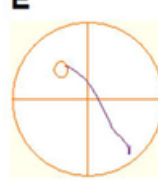

Control

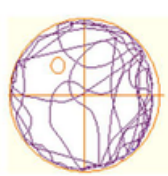

STZ
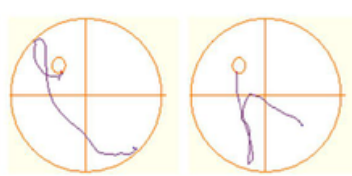

STZ+DIZE STZ+DIZE $(10 \mathrm{mg} / \mathrm{kg}) \quad(15 \mathrm{mg} / \mathrm{kg})$

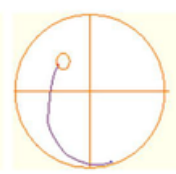

DIZE $(15 \mathrm{mg} / \mathrm{kg})$

\section{Figure 6}

ACE2/Ang-(1-7)/MasR activation rescue spatial recognition memory deficits in ICV STZ induced AD like phenotype in rats. Spatial learning and memory functions were assessed by Morris water maze test. A. The bar graph show escape latency (in sec), i.e., latency to reach the hidden platform. B. The bar graph shows mean path length (in $\mathrm{cm}$ ). C. Average swim speed of the rats in each session. D. Probe trial was performed to evaluate the time spent by rats in target quadrant E. Representative track plot of the path traced by an animal from each group. Data are expressed as mean \pm SEM of $n=6$ rats/group. Data were analyzed by repeated-measures two-way ANOVA, followed by Newman keuls multiple comparison post hoc test. ${ }^{\star} p<0.05,{ }^{\star \star} p<0.01$, ${ }^{\star \star \star} p<0.001$. \#p $<0.05$, \#\#p $<0.01$, \#\#\#p<0.001, * Session 1 vs Session 2, \# Session 1 vs Session 3; *Control vs STZ; \#STZ vs STZ+ DIZE; \$ STZ vs DIZE. 
A

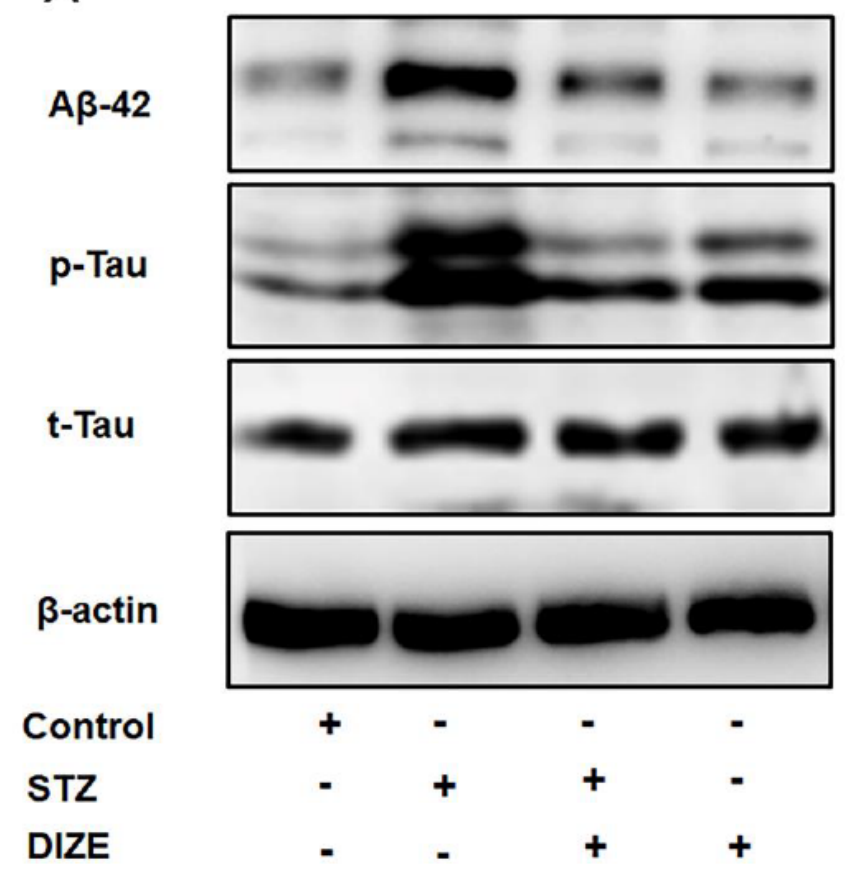

B
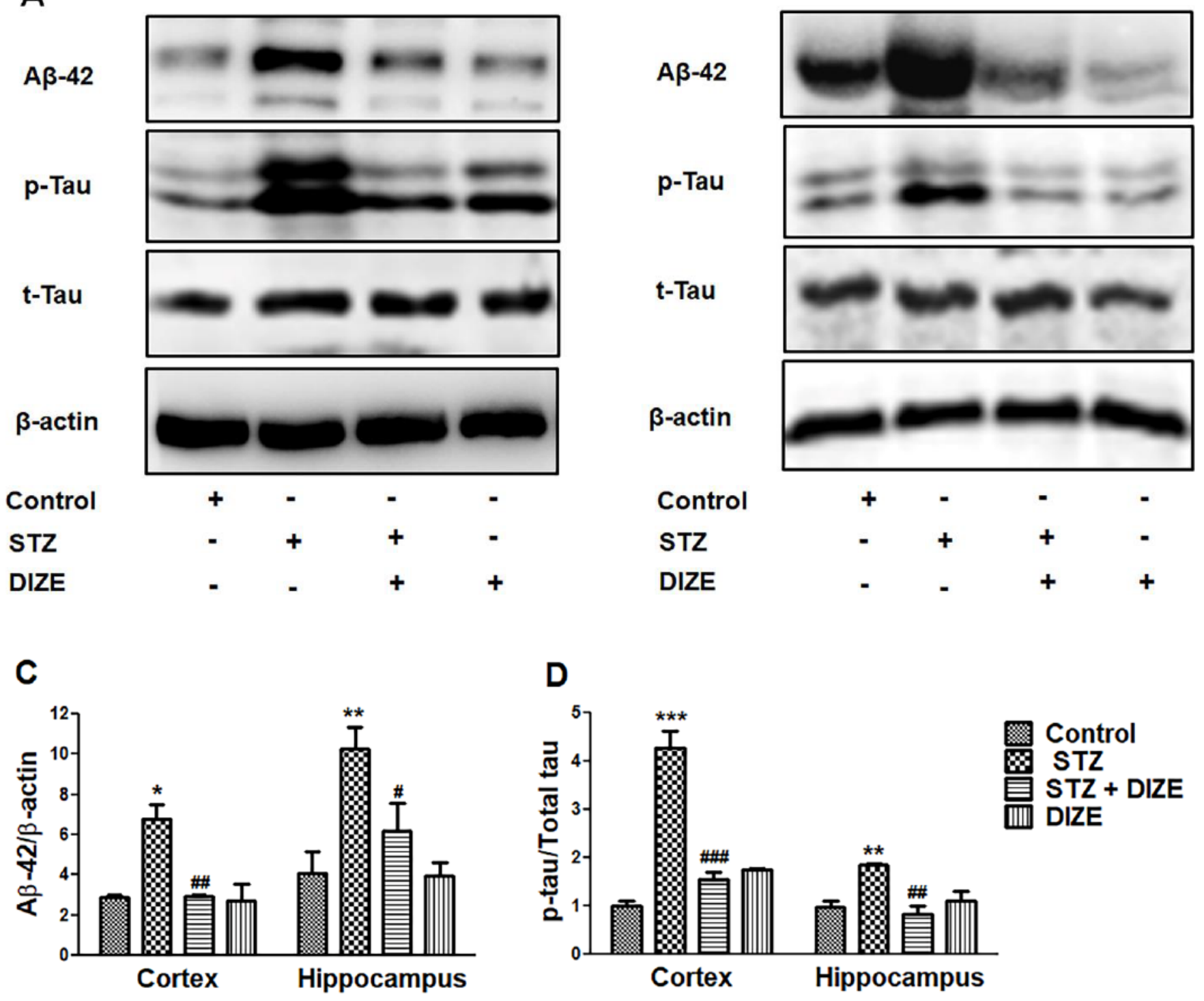

\section{D}

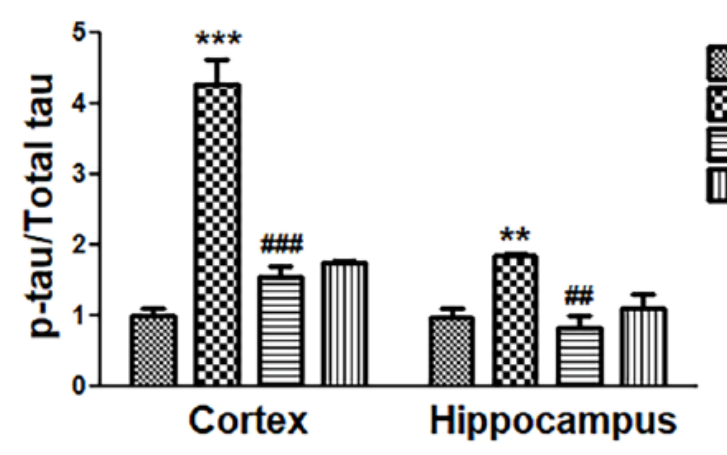

Figure 7

ACE2/Ang-(1-7)/MasR activation reduce $A \beta$ pathology in ICV STZ induced AD like phenotype in rats. Representative immunoblots show expression of $A \beta 42, p$-Tau, Tau and $\beta$-actin after treatment with DIZE in STZ lesioned rats in A. cortex B. hippocampus region. The bar graphs show quantification of relative protein density of $C$. $A \beta 42$ and D. $p$-Tau. Data are expressed as mean $\pm S E M$ of $n=3-4$. Data were analyzed by two-way ANOVA, followed by bonferroni post hoc test $\left({ }^{\star} \mathrm{P}<0.05,{ }^{\star *} \mathrm{P}<0.01,{ }^{\star \star \star} \mathrm{P}<0.001\right.$; \#P $<0.05, \# \# P<0.01, \# \# \# P<0.001)$. ${ }^{*}$ Control vs STZ; \#STZ vs STZ+ DIZE 

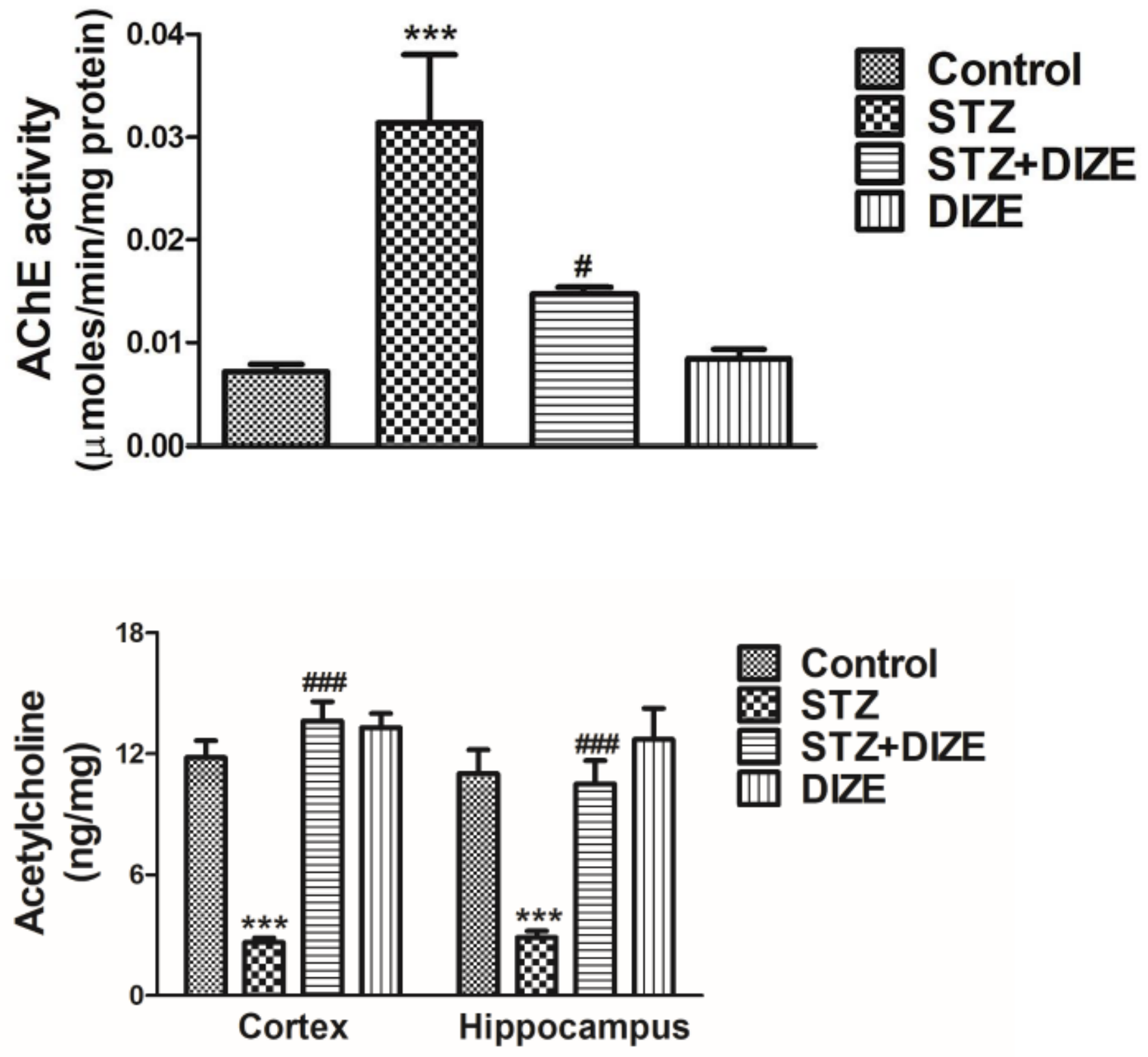

Figure 8

ACE2/Ang-(1-7)/MasR axis activation improve ACh level in STZ induced AD like phenotype in rats. A. Cholinergic deficit in neuronal cells. Graphical representation of acetylcholinesterase (AChE) enzyme activity in N2a cells exposed with STZ followed by DIZE treatment $(25 \mu \mathrm{M})$. B. Effect of DIZE treatment on cholinergic deficit in STZ lesioned rats. Histogram represents acetylcholine (ACh) level in rats lesioned with STZ followed by DIZE treatment (10 mg/kg, i.p.) in cortex and hippocampus brain region. Data are expressed as mean \pm SEM of $n=3-4$. Data were analyzed by one-way/two-way ANOVA, followed by 


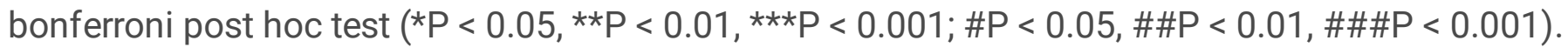
*Control vs STZ; \#STZ vs STZ+ DIZE.

\section{Supplementary Files}

This is a list of supplementary files associated with this preprint. Click to download.

- SI.docx 